\title{
Imprinting defects at human 14q32 locus alters gene expression and is associated with the pathobiology of osteosarcoma
}

\author{
Jingmin Shu ${ }^{1}$, Lihua $\mathrm{Li}^{2}$, Anne E. Sarver ${ }^{2}$, Emily A. Pope ${ }^{3}$, Jyotika Varshney², \\ Venugopal Thayanithy ${ }^{2}$, Logan Spector ${ }^{1,4}$, David A. Largaespada ${ }^{1,3,4}$, Clifford $\mathrm{J}$. \\ Steer $^{1,3,5}$, Subbaya Subramanian ${ }^{1,2}$ \\ ${ }^{1}$ Masonic Cancer Research Center, University of Minnesota, Minneapolis, MN, USA \\ ${ }^{2}$ Department of Surgery, University of Minnesota, Minneapolis, MN, USA \\ ${ }^{3}$ Department of Genetics, Cell Biology and Development, University of Minnesota, Minneapolis, MN, USA \\ ${ }^{4}$ Department of Pediatrics, University of Minnesota, Minneapolis, MN, USA \\ ${ }^{5}$ Department of Medicine, University of Minnesota, Minneapolis, MN, USA \\ Correspondence to: Subbaya Subramanian, e-mail: subree@umn.edu \\ Keywords: osteosarcoma, 14q32-locus, imprinting, DNA methylation, histone modifications
}

Received: July 13, 2015

Accepted: November 25, 2015

Published: January 21, 2016

\section{ABSTRACT}

Osteosarcoma is the most common primary bone malignancy affecting children and adolescents. Although several genetic predisposing conditions have been associated with osteosarcoma, our understanding of its pathobiology is rather limited. Here we show that, first, an imprinting defect at human 14q32-locus is highly prevalent $(87 \%)$ and specifically associated with osteosarcoma patients $<30$ years of age. Second, the average demethylation at differentially methylated regions (DMRs) in the 14q32-locus varied significantly compared to genome-wide demethylation. Third, the 14q32-locus was enriched in both H3K4-me3 and H3K27-me3 histone modifications that affected expression of all imprinted genes and miRNAs in this region. Fourth, imprinting defects at 14q32 - DMRs are present in triad DNA samples from affected children and their biological parents. Finally, imprinting defects at 14q32-DMRs were also observed at higher frequencies in an Rb1/Trp53 mutationinduced osteosarcoma mouse model. Further analysis of normal and tumor tissues from a Sleeping Beauty mouse model of spontaneous osteosarcoma supported the notion that these imprinting defects may be a key factor in osteosarcoma pathobiology. In conclusion, we demonstrate that imprinting defects at the 14q32 locus significantly alter gene expression, may contribute to the pathogenesis of osteosarcoma, and could be predictive of survival outcomes.

\section{INTRODUCTION}

Osteosarcoma is an aggressive bone cancer predominantly affecting children and young adolescents with a 5-year survival rate of $\sim 70 \%$ [1]. Despite significant advances in cancer treatment, the survival rate for osteosarcoma has remained static for the past 30 years. Genetic deficiencies such as mutations of TP53, RB, p14 and p16 have previously been reported as occurring frequently in osteosarcoma [2-5]. Silencing of Wnt inhibitory factor 1(WIF1) [6], p14ARF [7], and RASSF1A [8] by DNA hypermethylation and loss-of-imprinting in IGF2 and H19 have also been shown to occur in osteosarcoma $[9,10]$. Recently, we demonstrated that microRNAs (miRNAs) at the 14q32 locus are significantly downregulated in osteosarcoma, but not due to a loss of DNA copy number [11]. The $14 \mathrm{q} 32$ imprinted region is $\sim 1 \mathrm{Mb}$ in size and contains both paternally (DLK1, RTL1 and DIO3) and maternally (MEG3, MEG8 and DIO3OS) expressed genes [12, 13]. These imprinted genes have key roles in cellular functions [14-16], bone differentiation $[17,18]$, and can serve as markers for complete reprogramming of induced pluripotent stem (iPS) cells [19]. Interestingly, this imprinted locus also includes over 40 miRNAs, a subset of which cooperatively regulates cMYC expression in osteosarcoma [11]. It is therefore likely that dysregulated expression of genes and miRNAs resulting from disordered imprinting at this locus could contribute to the pathogenesis of osteosarcoma $[20,21]$. 
Genomic imprinting is a type of epigenetic inheritance through which differential expression of genes depends on parental origin (i.e., maternal or paternal) $[22,23]$. Typically, genomic imprinting occurs in pairs of genes that are located near each other. The expression of these imprinted genes is controlled by DNA methylation of unique parent-origin-alleles in the imprinting control regions (ICRs) or differentially methylated regions (DMRs) [24]. Loss of the monoallelic DNA methylation pattern in the ICRs or DMRs, also known as loss-ofimprinting, can cause changes in expression of imprinted genes in the region. For example, loss-of-imprinting at the IGF2 locus has been found in Wilms' tumor $[25,26]$, colorectal [27], and other cancer types [28]. The three DMRs in the 14q32 locus can regulate the imprinted genes and miRNA clusters in the region [29, 30].

To determine if epigenetic alteration(s) of the $14 \mathrm{q} 32$ locus is associated with osteosarcoma, we evaluated the DNA methylation levels of these DMRs and studied histone modifications in normal bone tissues and osteosarcoma patient samples. We also determined the imprinting status of the $14 \mathrm{q} 32$ locus in buccal DNA samples from osteosarcoma patients and their biological parents. Further, we studied the methylation patterns at DMRs of the homologous regions in two mouse models of spontaneous osteosarcoma. Our results suggest that imprinting defects in humans is associated with the pathobiology of osteosarcoma.

\section{RESULTS}

\section{Imprinting defects at 14q32 DMRs in osteosarcoma}

There are three DMRs in the 14q32-imprinted region, which can regulate the entire imprinted gene cluster [29]. Two of these DMRs, DMR-1 and DMR-2, are intergenic (IG-DMRs) and are located in close proximity to each other between the DLK1 and MEG3 genes. The third, DMR-3, is located in the promoter region of the MEG3 gene (MEG3-DMR). By bisulfite TA cloning and sequencing we determined the DNA methylation pattern in genomic regions designated site $\mathrm{A}$ (which includes DMR-2) and two $\mathrm{CpG}$ islands at sites B and $\mathrm{C}$ (Figure 1A). DNA methylation analysis indicated that in normal bone tissues, the imprinting pattern $(\sim 50 \%$ DNA methylation level with one allele densely methylated and another free of methylation) was identified at site A (Figure 1B). However in osteosarcoma SaOS2 cells, an imprinting defect of hypermethylation was found at site $\mathrm{A}$ compared to normal bone tissues. $\mathrm{CpG}$ island sites $\mathrm{B}$ and $\mathrm{C}$ were also densely methylated $(\sim 90 \%)$ at both alleles. DNA methylation analysis confirmed the locations of these DMRs in normal bone tissues and SaOS2 cells.

To determine whether imprinting defects at these DMRs are associated with osteosarcoma, we analyzed the methylation pattern of all three DMRs (DMR-1, -2 and -3 ) (Figure 1C) in 8 normal bone tissues and 32 osteosarcoma samples (Supplementary Table 1) by bisulfite-pyrosequencing. With the exception of 5 osteosarcoma samples (FT-7, -422, -426, -430 and -436), all samples were collected during local control surgeries prior to neoadjuvant chemotherapy and/or radiation. Based on our sample age distribution [31], we defined the early- and late-onset OS. 23 samples were early-onset OS (<30 years) and 9 samples were late-onset OS ( $>30$ years). Our DNA methylation analysis revealed that imprinting defects, specifically hypomethylation, at DMRs were detected in most of the early-onset osteosarcoma patient samples but were not present in the late-onset samples (Figure 1D). DMR-2 appeared to be most prone to imprinting defects.

\section{$14 q 32$ index identifies normal/early- and late-onset osteosarcoma}

To test whether imprinting defects at the $14 \mathrm{q} 32$ locus were the consequence of global hypomethylation, we assessed the genome-wide methylation status in osteosarcomas by measuring the methylation of LINE-1, representing 17\% human genomic DNA [32] (Figures $1 \mathrm{E}$ and $2 \mathrm{~A}$ ). We found that the methylation status of a single allele of LINE-1 decreased by $\sim 5 \%$ in both early- and late-onset osteosarcoma. However, the methylation decrease at 14q32-DMRs was $~ 19 \%$ in earlyonset osteosarcoma and was significantly higher than that of LINE-1 $(P=0.0046)$. Hypomethylation at the 14q32locus was therefore not entirely the result of genome-wide demethylation in early-onset osteosarcoma. In contrast, the hypomethylation at $14 \mathrm{q} 32$ in late-onset osteosarcoma samples was $\sim 6 \%$, similar to that of LINE-1, suggesting that demethylation in late-onset osteosarcoma was likely due to global hypomethylation.

A pattern of either hyper- or hypomethylation at DMRs signifies imprinting defects. Although hypomethylation was the predominant pattern at DMR-2 in the majority of cancers compared to normal bone tissues, a few cases did present with hypermethylation at 14q32-DMRs. Thus, we calculated the extent of imprinting defects as the absolute difference of DNA methylation deviation from the normal imprinted-DMR levels (50\%). Both gain and loss of methylation at DMR were defined as loss-of-imprinting and both types of changes led to similar gene expression patterns, therefore we used the absolute value of the difference between samples and the theoretical normal $(50 \%)$ to define the extent. We termed this quantitative deviation of imprinting the ' $14 q$-index' $(14 q-I)$. The $14 q$-index was calculated as the average extent of imprinting defects at all three DMRs using the following formula:

$14 q$-index $=\left(\mid\right.$ DNAmethy ${ }_{\mathrm{DMR}-1}-50|+|$ DNAmethy $_{\mathrm{DMR}-2}$ $-50|+|$ DNAmethy $\left.{ }_{\mathrm{DMR}-3}-50 \mid\right) / 3$ 
Based on the above equation, the calculated $14 q$-index for normal bone tissues was 7.0. It was notable that normal/early-onset osteosarcoma (12-30 years) samples showed a significantly higher $14 q$-index at 18.6. The average 14q-index was 8.5 for late-onset osteosarcoma ( $>30$ years), a non-significant change versus normal bone tissues (Figure 2B). Based on a 95\% confidence interval (CI), we defined imprinting defect as a $14 \mathrm{q}$-index values $>8.5$. Twenty of the $23(87 \%)$ early-onset osteosarcomas were $14 \mathrm{q}-\mathrm{I}(+)$. However, in the late-onset group only 5 of 9 $(56 \%)$ were positive and the degree of $14 q$-index changes was not as dramatic as that of the early-onset group.

\section{Loss of 14q32-locus imprinting is unique to osteosarcoma}

Next, we investigated whether the imprinting defect was limited to DMRs in the 14q32-locus or extended to others. We tested the DNA methylation levels of three other known DMRs at the H19, MEST and PEG3 imprinted gene clusters in normal bone and osteosarcoma samples. Based on a $95 \%$ confidence interval of normal bone tissue, $\sim 59 \%$ (19 out 32) of osteosarcoma samples showed imprinting defects at H19-DMRs (Figure 2B). The correlation between imprinting defects at $14 \mathrm{q} 32-\mathrm{DMRs}$ and H19-DMR was $0.78\left(\mathrm{R}^{2}=0.61\right)$, potentially implicating both loci in tumor development (Figures 1E, 2C). The methylation patterns of H19-DMRs, were much more complex than that of the 14q32-locus, which had both gain- and loss-of DNA methylation (Figure 1E) and the frequency of loss-of-imprinting at H19 was much lower than that at 14q32-locus. Imprinting defects were not found in DMRs of MEST and PEG3 and there was no correlation between either of these two genes and the 14q32-locus (Figure 2B and 2C).

We then tested whether imprinting defects at the 14q32-locus were unique to osteosarcoma or widespread among different cancer types. The DNA methylation levels of 14q32-, H19-, MEST- and PEG3-DMRs were determined using 13 cell lines representing 6 different cancer types (Figure 2D). Hypomethylation at $14 \mathrm{q} 32$ IG-DMR (DMR-1), which was characteristic of human osteosarcoma tissue samples, was also observed in osteosarcoma cell lines SaOS2 and U2OS. However hypermethylation patterns were observed in osteosarcoma cell lines MG63 and HOS both characterized as having an osteoblastic phenotype. There were no consistent patterns of change in DNA methylation status in the 6 additional cancer types tested, indicating that hypomethylation of this set of DMRs may be a distinguishing feature of osteosarcoma.

\section{Downregulation of $14 q 32$ locus genes is associated with imprinting defects}

Imprinting defects at DMRs have been shown to regulate the expression of genes within the locus. To determine the effects of imprinting defects at 14q32DMRs on gene expression, we measured the expression levels by qRT-PCR of 6 imprinted genes in this locus including paternal (DLK1, RTL1, and DIO3) and maternal (MEG3, MEG8, and DIOAS) genes expressed in 4 normal bone tissue samples, six $14 \mathrm{q}-\mathrm{I}(-)$ and eight $14 \mathrm{q}-\mathrm{I}(+)$ osteosarcoma samples (Figure 3). RTL1, DIO3, and MEG3 were relatively highly expressed in normal bone tissues, while $D L K 1, M E G 8$ and $D I O 3 A S$ were expressed at lower levels. Most of the imprinted genes at the 14q32-locus (with the exception of MEG8) were downregulated in 14q- I(-) samples, and further decreased in $14 \mathrm{q}-\mathrm{I}(+)$ samples.

To evaluate the co-expression of imprinted genes and miRNAs at the $14 \mathrm{q} 32$ locus, we analyzed the expression of DLK1-DIO3 cluster genes (DIO3, DLK1, $M E G 3$, and $M E G 8$ ) and representative $14 \mathrm{q} 32$ miRNAs (miR-134, miR-154, and miR-382) in an independent set of 43 osteosarcoma tumor samples. In the majority of tissues analyzed, $14 \mathrm{q} 32$ miRNA expression was correlated with DLK1-DIO3 cluster genes, particularly with $M E G 3$ and MEG8 (Figure 3C).

\section{Histone modifications at the $14 \mathrm{q} 32$ imprinted region}

Histone modifications regulate long distance gene expression. We measured histone modification patterns at the 14q32-locus with ChIP assays by mapping the active marker H3K4-me3 and the silence markers H3K27-me3, H3K9-me2 and H3K9-me3 in normal bone tissues, $14 \mathrm{q}-\mathrm{I}(-)$ and $14 \mathrm{q}-\mathrm{I}(+)$ osteosarcoma samples. Among the normal samples, we found that the imprinted gene cluster from $D L K 1$ to $D I O 3$ shares a similar histone modification pattern, including H3, H3K4-me3, H3K27-me3, H3K9me2 and H3K9-me3 (Figure 4A). The 14q32-locus was enriched with both active marker H3K4-me3 and silence markers $\mathrm{H} 3 \mathrm{~K} 27-\mathrm{me} 3$, H3K9-me2, and H3K9-me3 in normal bone tissues (Figure 4A). GAPDH, cMYC, p16, and RARB were used as controls; and IgG was used as a negative antibody control to evaluate the enrichment of histone modification markers [33] (Supplementary Figure 1A-1D).

Because the entire imprinted region shares a similar histone modification pattern, we used levels of different histone markers at IG-DMR to represent the histone modification at this genomic region. H3K4-me3 at 14q32 IG-DMR was lower than $G A P D H$, but was $\sim 80$-fold higher than the $\operatorname{Ig} G$ negative control. On the other hand, H3K27-me3 at 14q32 IG-DMR was 1.6-fold higher than at $R A R B$ and was $\sim 180$-fold higher than IgG negative control (Supplementary Figure 1E-1F). Similarly, H3K9-me2 and H3K9-me3 were detected at much higher levels at IG-DMR than IgG. Based on these observations we concluded that H3K4-me3, H3K27-me3, H3K9-me2, and H3K9-me3 were enriched at the $14 \mathrm{q} 32$-imprinted region.

We examined the changes to histone modification in osteosarcoma and looked for differences between 14q-I(-) 
A

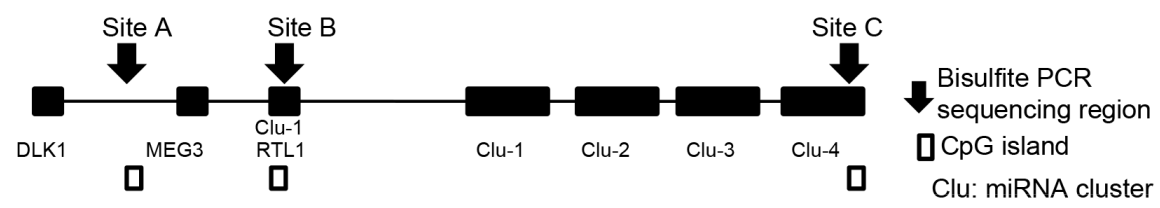

B

Normal bone

Site A

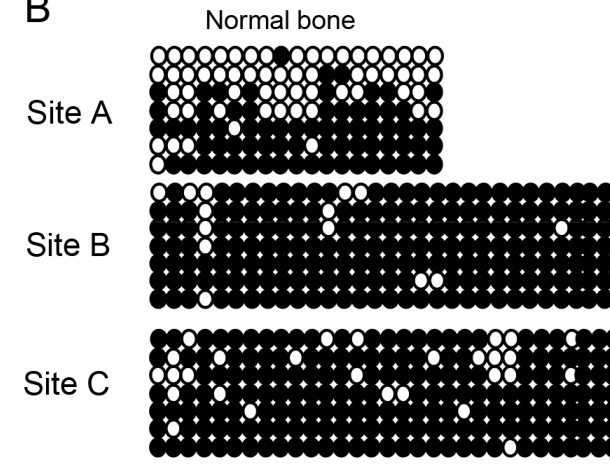

SaOS2 cell line

Clu: miRNA cluster

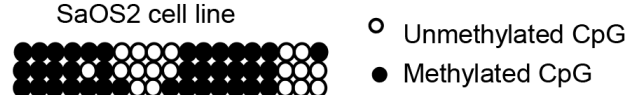

C

DMR-1 DMR-2 DMR-3

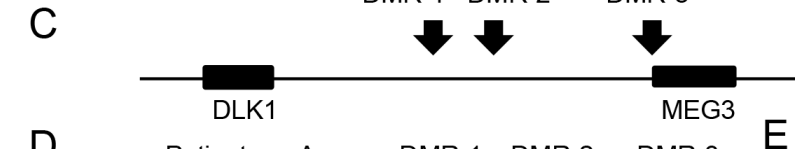

$\mathrm{D}$
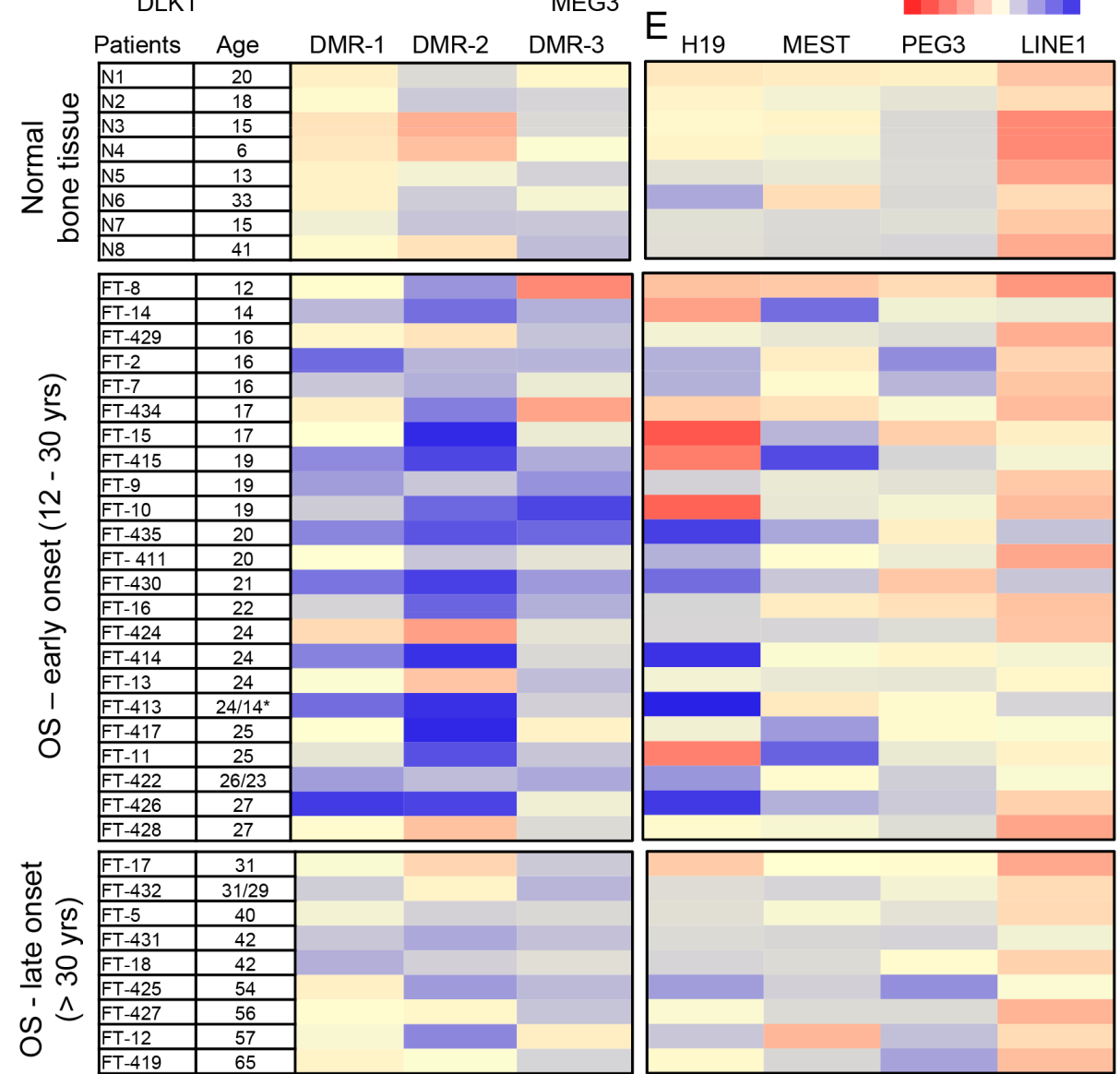

Figure 1: Confirmation of IG-DMR of 14q32 imprinted locus and DNA methylation changes of DMRs at the 14q32locus. (A) Schematic map of the 14q32 imprinted locus. DNA methylation levels of sites A, B, and C were studied by bisulfite TA cloning and sequencing. (B) DNA methylation pattern of sites A, B and C in normal bone tissue and SaOS2 cell line. Site A includes DMR2 in Figure 1C. Each row represents a single clone and each column represents a CpG site. (C) Three DMRs at 14q32-locus. DMR-1 and DMR-2 are IG-DMRs, and DMR-3 is MEG3-DMR. (D) DNA methylation levels of DMRs of 14q32-locus, 8 normal bone tissue and 32 osteosarcoma patient tumor tissue samples analyzed by bisulfite pyrosequencing. (E) DNA methylation levels of DMRs of three other imprinted loci, including H19, MEST and PEG3, and methylation levels of LINE1. *Age: 24/14 represent tissues from relapse osteosarcoma samples (24 years) and primary at 14 years. 

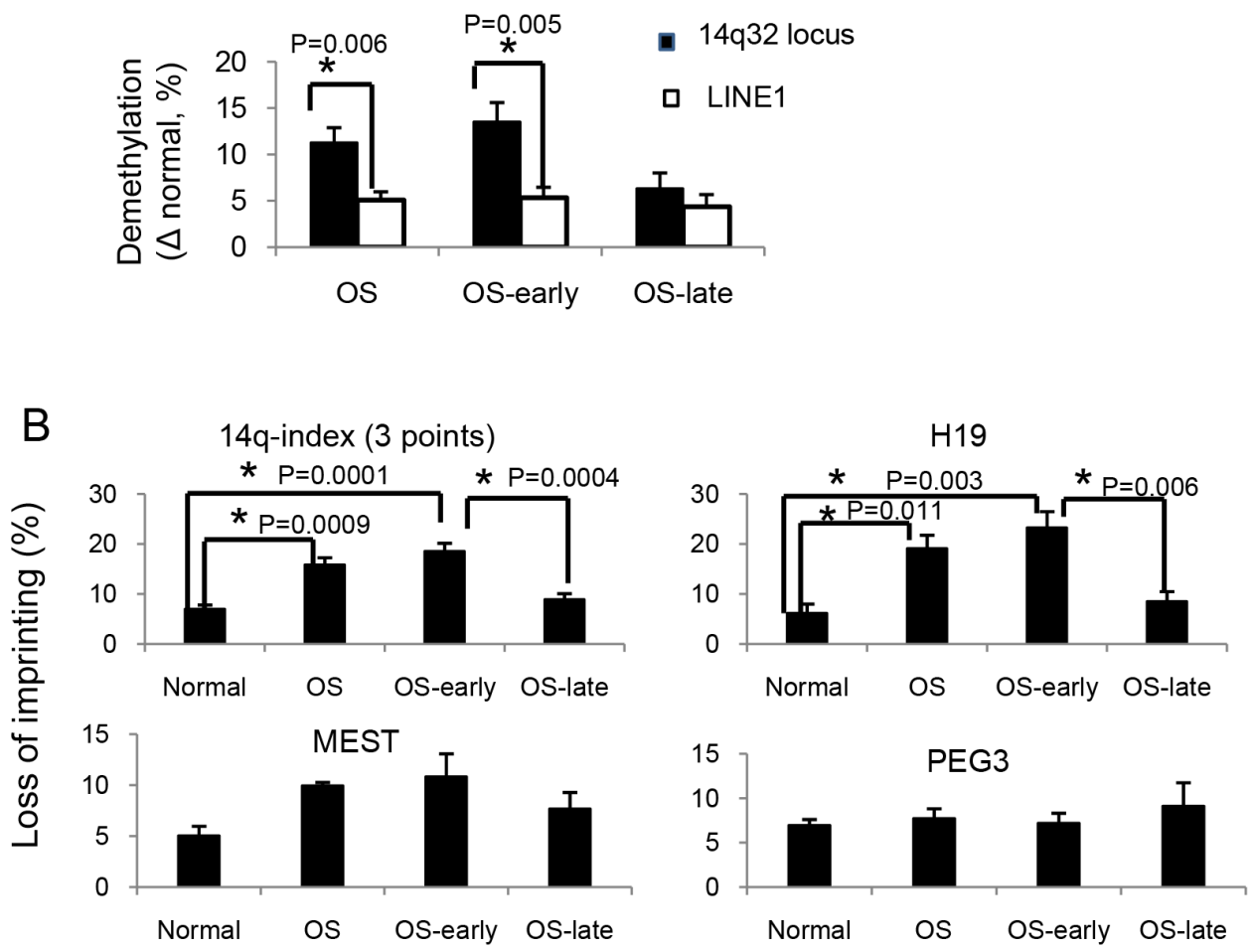

C
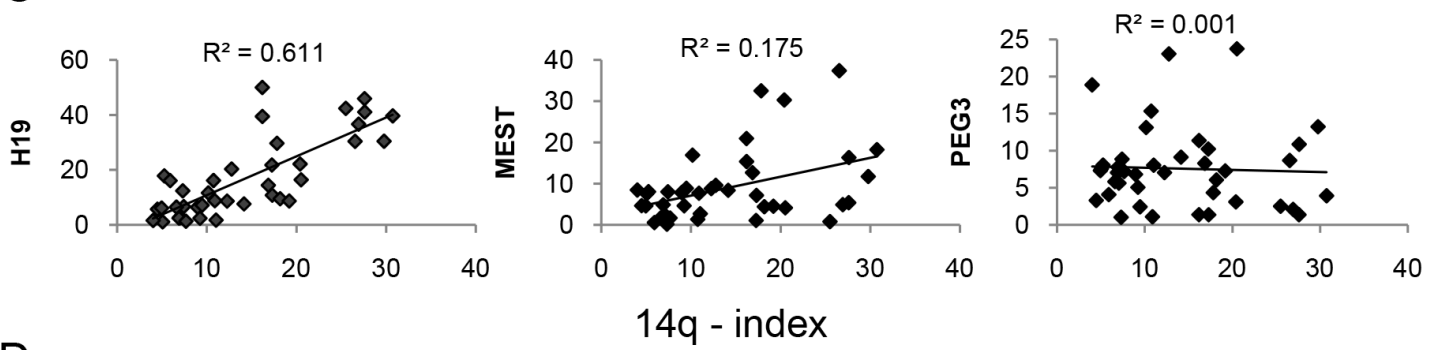

D

\begin{tabular}{|l|l|c|c|c|}
\hline Origin & Cell lines & DMR1 & DMR2 & DMR3 \\
\hline \multirow{2}{*}{ Colon cancer } & SW480 & 92 & 94 & 75 \\
\cline { 2 - 5 } & HT29 & 92 & 94 & 71 \\
\hline \multirow{2}{*}{ Breast cancer } & MCF-7 & 93 & 94 & 79 \\
\hline \multirow{2}{*}{$\begin{array}{l}\text { Malignant peripheral } \\
\text { nerve sheath tumors }\end{array}$} & MPNST-14 & 51 & 84 & 43 \\
\cline { 2 - 5 } & MPNST-724 & 63 & 89 & 43 \\
\hline \multirow{2}{*}{ Rhabomyosarcoma } & RD & 96 & 94 & 46 \\
\cline { 2 - 5 } & RH30 & 91 & 72 & 36 \\
\hline \multirow{3}{*}{ Synovial sarcoma } & Fuji & 91 & 83 & 9 \\
\cline { 2 - 5 } & SYO-1 & 94 & 95 & 6 \\
\hline \multirow{3}{*}{ Ssteosarcoma } & SaoS2 & 9 & 95 & 35 \\
\cline { 2 - 5 } & U2OS & 6 & 92 & 33 \\
\cline { 2 - 5 } & MG63 & 66 & 93 & 93 \\
\cline { 2 - 5 } & HOS & 89 & 73 & 90 \\
\hline
\end{tabular}

\begin{tabular}{|c|c|c|}
\hline H19 & MEST & PEG3 \\
\hline 94 & 94 & 97 \\
\hline 78 & 93 & 95 \\
\hline 2 & 75 & 89 \\
\hline 55 & 56 & 40 \\
\hline 56 & 55 & 36 \\
\hline 97 & 93 & 94 \\
\hline 84 & 48 & 40 \\
\hline 3 & 54 & 40 \\
\hline 3 & 36 & 73 \\
\hline 15 & 90 & 39 \\
\hline 1 & 89 & 23 \\
\hline 75 & 94 & 86 \\
\hline 76 & 48 & 91 \\
\hline
\end{tabular}

Figure 2: Imprinting defects at the 14q32 locus in osteosarcoma. (A) Significant differences in demethylation levels between DMRs at 14q32-locus and LINE1 in osteosarcomas. (B) Determination of imprinting defects at 14q32 DMRs, H19, MEST and PEG3 in normal bone tissue (normal), osteosarcoma samples (osteosarcoma), osteosarcoma early-onset (osteosarcoma-early) and late-onset (osteosarcoma-late) samples. The imprinting defect extent is defined as the absolute methylation difference between patient samples and the proposed normal imprinted DMR levels (50\% methylation). (C) Correlations between 14q-index and imprinting defects in H19, MEST, and PEG3, respectively. (D) DNA methylation patterns of 3 DMRs at 14q32-locus and 3 other imprinted loci in cancer cell lines representing 6 cancer types. ${ }^{*} P<0.05$. Abbreviations used: OS: total OS samples, including both early- and late- onset samples; OS-early: early-onset OS samples $(n=23)$; OS-late: late-onset OS samples $(n=9)$. 
and $14 \mathrm{q}-\mathrm{I}(+)$. We found the total $\mathrm{H} 3$ levels were decreased in both $14 \mathrm{q}-\mathrm{I}(-)$ and $14 \mathrm{q}-\mathrm{I}(+)$ samples (Supplementary Figure 2A). In 14q-I(+) samples, H3K4-me3, H3K9-me2, and H3K9-me3 were increased, and H3K27-me3 was decreased. But in $14 \mathrm{q}-\mathrm{I}(-)$ samples, all of the histone markers showed a decrease. After normalizing to the level of $\mathrm{H} 3$, the majority of histone markers were increased in $14 \mathrm{q}-\mathrm{I}(+)$ osteosarcoma group (Figure 4B and Supplementary Figure 2), but were decreased or unchanged at most of imprinted gene loci in $14 \mathrm{q}-\mathrm{I}(-)$ osteosarcoma. We deduced that all of the imprinted genes were regulated by histone modification as a single unit and silenced by the increase of three silencing markers in the $14 \mathrm{q}-\mathrm{I}(+)$ region.

To confirm that the sonication process did not preferentially disrupt either allele, we used total input as a control. In all three groups, the DNA methylation levels of the input samples were consistent with the results we obtained directly from patient DNA, suggesting that sample preparation during the ChIP assay did not affect the measurements.

DNA methylation levels for both H3K4-me3 and H3K27-me3 ChIP samples shared a similar pattern with the input control in all samples (Figure 4C), confirming that the H3K4-me3 and H3K27-me3 were equally present at both maternal and paternal alleles.

\section{Proteins encoded by the $14 q 32$ locus act as tumor suppressors}

It has previously been reported that $M E G 3$ is a tumor suppressor gene [15], but RTL1 and DIO3 remain candidate genes of interest and have not been well studied in osteosarcoma. Transient overexpression of $D L K 1$, RTL1 or DIO3 individually in SaOS2 cells decreased cell viability by $\sim 30 \%$, compared to cells transfected with control plasmids (Figure 4D). Individual transfection of DLK1, RTL1 or DIO3 also significantly increased apoptosis in SaOS2 cells (Figure 4E). Our previously published work has demonstrated that several miRNAs in this area can also function as tumor suppressors in the context of osteosarcoma [11].

\section{Imprinting instability at $14 q 32$ locus}

It is likely that osteosarcoma patients inherit, at least in part, imprinting instability from their parents, which predisposes them to the early-onset oncogenesis typical of osteosarcoma. To test this hypothesis, we measured DNA methylation levels of two IG-DMRs at the $14 \mathrm{q} 32$ locus in buccal samples from 12 unrelated normal subjects (median age 26 years), and 10 sets of triad samples (10 osteosarcoma patients plus their biological parents). Due to the rapid turnover of the buccal mucosa, epithelial cells are subject to an increased risk, compared to normal bone tissue, of changes in DNA methylation status and of development of loss-of-imprinting resulting from age-related methylation mechanisms [34]. In unrelated normal individuals, we found the average methylation level of DMR-1 was 53\% and DMR-2 was 64\%, likely due to normal age-related increases in DNA methylation. The normal range of DNA methylation in buccal tissues, was therefore defined as 51-55\% at DMR-1 and 61-67\% at DMR-2 (using a 95\% CI) (Supplementary Table 3A).

Hypermethylation imprinting defects at IG-DMRs, especially DMR-1, were detected in all of the analyzed osteosarcoma patient samples and, importantly, in all parent samples. There was a significant difference in DMR-1 $(P<0.0001)$ and DMR-2 $(P<0.05)$ DNA methylation levels between unrelated normal healthy samples and those in the osteosarcoma patient or parent samples (Figure 5A, 5B and Supplementary Table 3B). Patient DMR methylation patterns appear to be correlated with their respective parents' patterns (Figure 5C-5D). The Pearson's correlation coefficient (Pearson's r) is 0.5 between osteosarcoma patients and their fathers at DMR-1, and is 0.63 between osteosarcoma patients and their mothers at DMR-2 (Supplementary Table 3C). This suggests that the imprinting defect at $14 \mathrm{q} 32$ might be inherited from existing parental imprinting instability, especially from the paternal side.

\section{Imprinting defects did not result from pre-existing mutations in spontaneous osteosarcoma mouse models}

To determine if imprinting defects at the $14 \mathrm{q} 32$ locus were a result of pre-existing mutations during osteosarcoma development, we studied tumor tissues using a spontaneous osteosarcoma model in T2/onc, $p 53^{\mathrm{R} 270 \mathrm{H} /+}$, OSx-Cre, ROSA26-LSL-SB11 mice. These mice express a $p 53^{\mathrm{R} 270 \mathrm{H}}$ point mutation and allow random insertional mutagenesis using the Sleeping Beauty $(S B)$ transposon system. Consistent with a previous report [35], $\sim 60 \%$ of $p 53^{\mathrm{R} 270 \mathrm{H} /+}$ mice developed osteosarcoma with an average age of onset of $\sim 16$ months. In T2/onc; p5 $53^{\mathrm{R} 270 \mathrm{H} /+} ; \mathrm{OSx}$-Cre; ROSA26-LSL-transposase mice, 70\% of mice developed osteosarcoma by $\sim 11$ months with the earliest case appearing at 8 months. $S B$ mutagenesis led to accelerated tumor formation compared to the $p 53^{\mathrm{R} 270 \mathrm{H} /+}$ mice.

We determined the DNA methylation changes of IG-DMR at the mouse $12 \mathrm{qF}$ locus (homologous to human 14q32), with bone tissues from normal mice as controls. In normal bone samples, the mean DNA methylation level was 64\% (95\% CI: 55\% - 73\%) (Figure 6A and Supplementary Table 4A). In Trp53-R270 H/SB tumor samples, 44\% (11 out of 25) showed imprinting defects, which was comparable to the prevalence of imprinting defects in late-onset human osteosarcoma ( 56\%), suggesting that late-onset osteosarcoma in humans is more likely to be caused by spontaneous somatic mutations. In contrast to human osteosarcoma samples, imprinting 
A

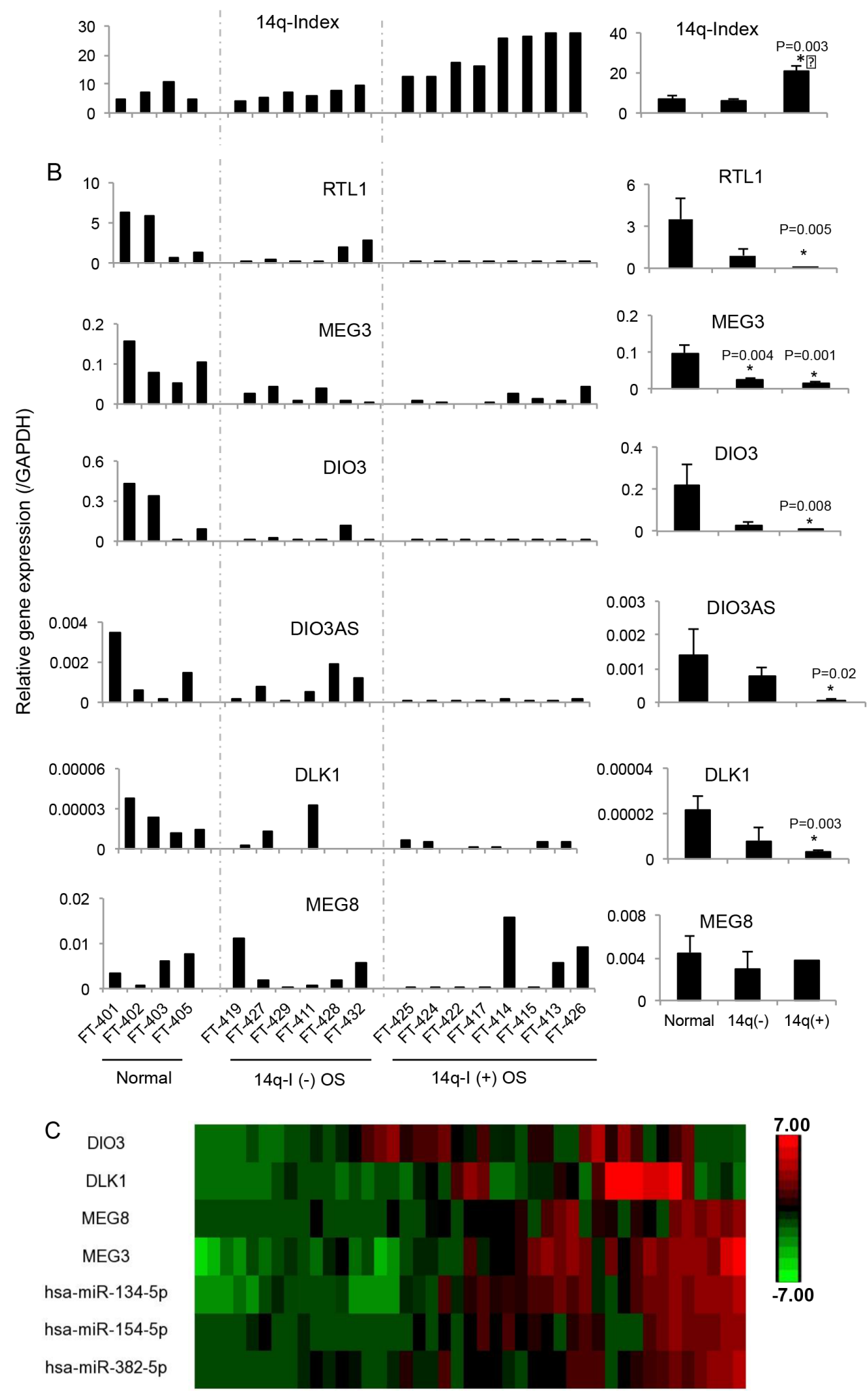

Figure 3: Downregulation of genes by imprinting defects at the 14q32-locus. (A) 14q index (14q-I) of four normal bone tissue samples, six 14q-I(-) osteosarcoma and eight 14q-I $(+)$ osteosarcoma samples. (B) mRNA levels of six imprinted genes by qRT-PCR with GAPDH used as control. The right column indicates the average and standard error of the imprinted gene expression levels in 3 different groups, including normal bone tissues, $14 \mathrm{q}-\mathrm{I}(-)$ osteosarcoma and 14q-I(+) osteosarcoma groups, respectively. ${ }^{*} P<0.05$. (C) Relative expression levels of representative DLK1-DIO3 cluster mRNAs and 14q32 miRNAs from an independent cohort of 43 osteosarcoma patient samples. 
A

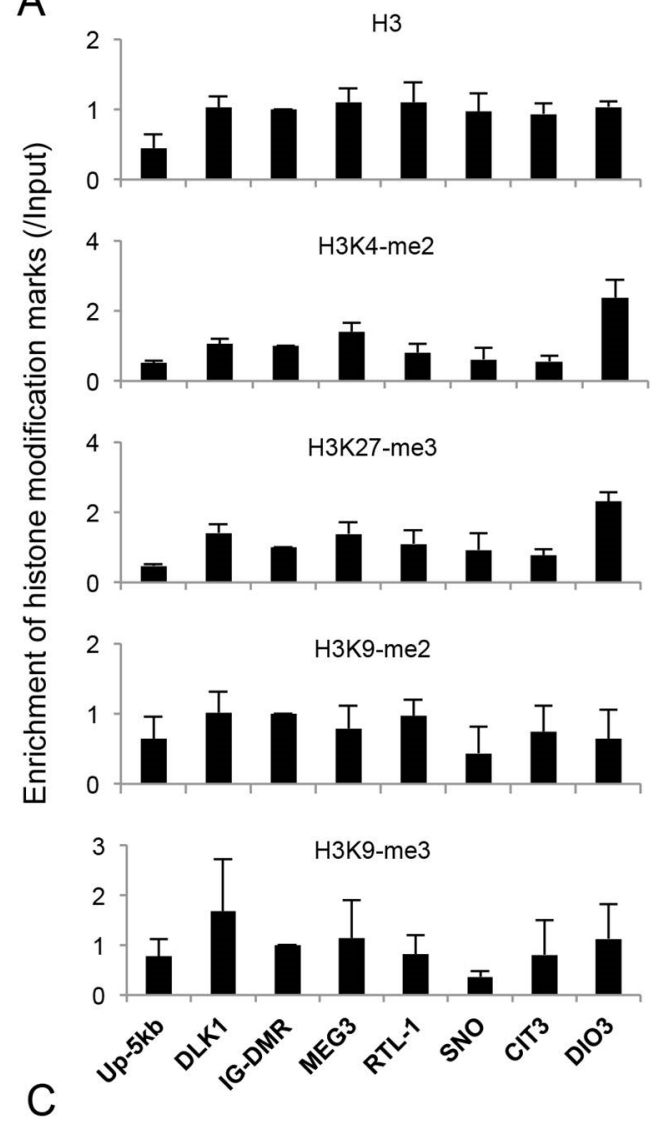

B

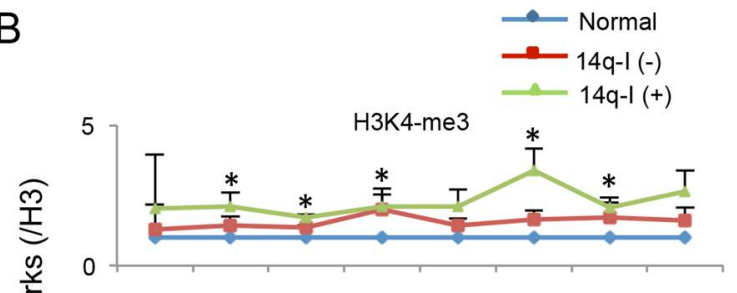

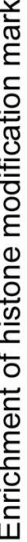

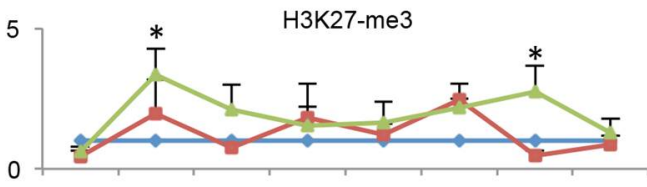

0

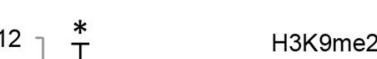

6

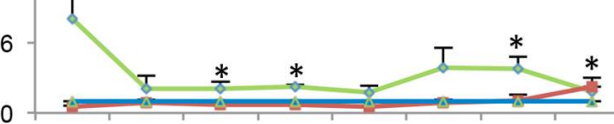

6 H3K9me3

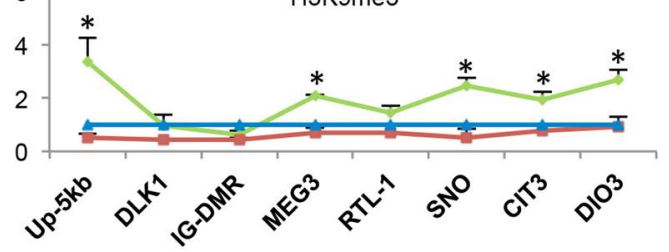

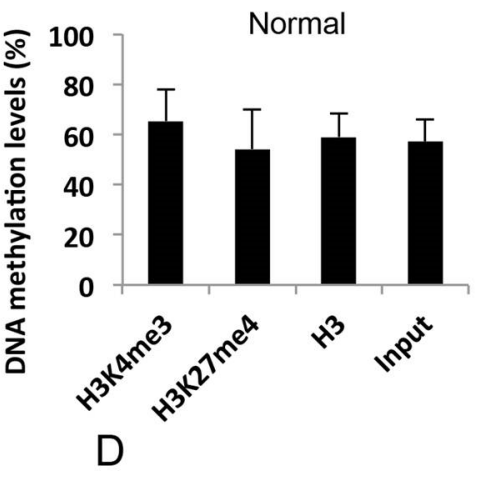

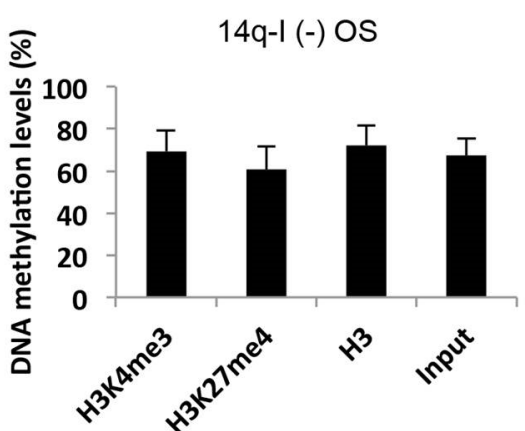

E
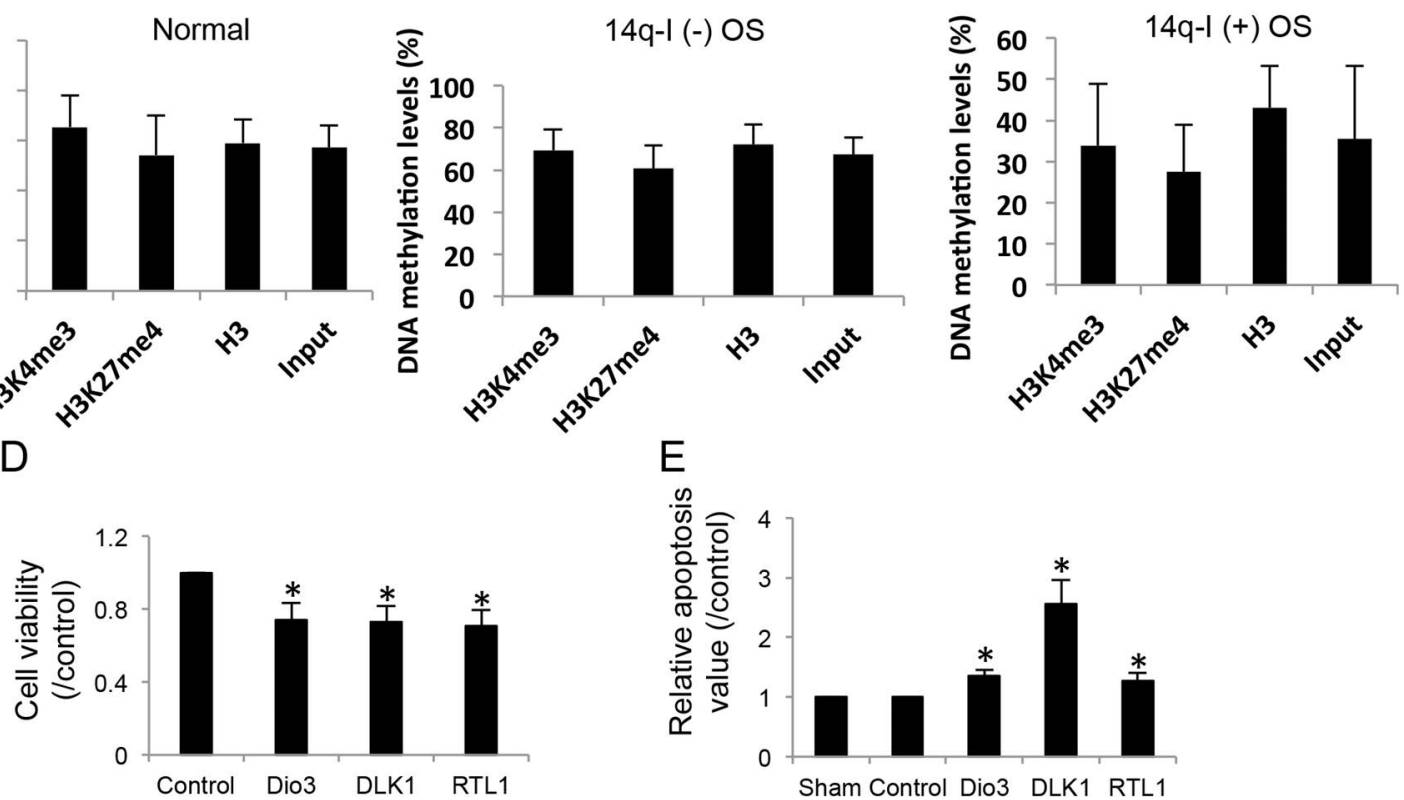

Figure 4: Histone modifications around imprinted genes and their potential tumor suppressor functions at the 14q32locus. (A) Enrichment of H3, H3K4-me3, H3K27-me3, H3K9-me2 and H3K9-me3 at the promoter regions of imprinted genes in normal bone tissues. Input was used as internal control. Up-5kb: site $\sim 5 \mathrm{~kb}$ upstream of the promoter of DLK1; SNO: small non coding RNA region; CIT: miRNA cluster 3 region. (B) H3K4-me3, H3K27-me3, H3K9-me2 and H3K9-me3 enrichment normal bone tissues, 14q-I(-) and $14 \mathrm{q}-\mathrm{I}(+)$ osteosarcoma samples. $\mathrm{H} 3$ was used as internal control. ${ }^{*} P<0.05$. (C) DNA methylation levels of the ChIP samples pulled down by H3, H3K4-me3, and H3K27-me3 antibodies in normal bone tissues, 14q-I(-) osteosarcoma and 14q-I(+) osteosarcoma samples. Input sample was used as control. (D) Significant decrease of cell viability by overexpression of DIO3, DLK1 and RTL1 in SaOS2 cells. Paired $t$-test was performed. ${ }^{*} P<0.05$. (E) Increased apoptosis by overexpression of DIO3, DLK1 and RTL1 in SaOS2 cells. pCDNA3.1 empty vector was used as control. Sham represents $\mathrm{SaOS} 2$ cells without plasmid transfection. Results represent the average of three independent transfections. ${ }^{*} P<0.05$. 
defects in these mice were due to hypomethylation (3 out of 25) or hypermethylation (8 out of 25). As reported earlier, it is likely that different regulatory mechanisms are involved in human and mouse at this locus [29]. In humans, DMRs are located outside CpG islands, while in mice the DMRs are located within $\mathrm{CpG}$ islands, which are better protected against methylation changes. The fact that $12 \mathrm{qF}$ imprinting defects were found in only $44 \%$ of $S B$-induced osteosarcoma suggested that $12 \mathrm{qF}$ imprinting defects were not caused by osteosarcoma formation, but might instead be one of the underlying mechanisms predisposing the tumor's development.

\section{Imprinting defects at $12 \mathrm{qF}$ were related to osteosarcoma development in p53/Rb mutation mouse model}

To further establish the role of imprinting defects at $12 \mathrm{qF}$ in osteosarcoma development, we generated an osteosarcoma mouse model with both p53 and $\mathrm{Rb}$ mutations (Figure 6B-6C). 25 mice with osteosarcoma representing various tumor locations (20 limb, 3 pelvis,
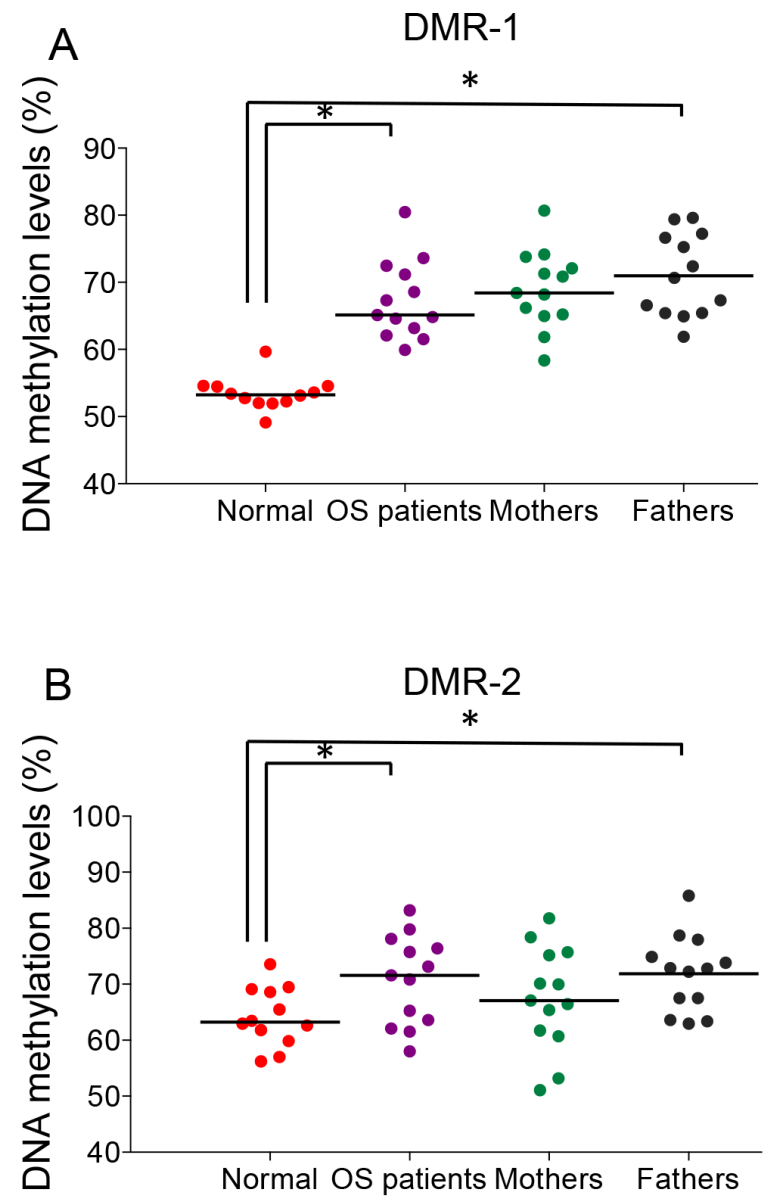

1 neck, and 1 soft tumor inside the chest wall) were included in the study. We were able to determine the DNA methylation levels at the $12 \mathrm{qF}$ IG-DMR locus in 24 of these samples. Based on $95 \%$ CI of normal bone tissue, we defined that normal methylation range was 72 76\% (Supplementary Table 5). Imprinting defects were found in all osteosarcoma samples, consistent with observations in human osteosarcoma (87\%). We found both hypomethylation $(66.7 \% ; 16$ out of 24$)$ and hypermethylation $(33.3 \% ; 8$ out of 24$)$, similar to the previous mouse osteosarcoma samples (Figure 6D).

We examined the expression levels of the homologous 14q32 locus imprinted genes in these mouse osteosarcoma samples. We found that Dio3 and Rtl1, the paternally expressed genes, were dramatically decreased in the DMR hypomethylated samples but had no significant change in the hypermethylated samples (Figure 6E), again consistent with the human osteosarcoma samples (Figure 3). The maternally expressed genes Meg3 and Rian had no significant changes in expression although an increased trend was observed (Figure 6E), in contrast to the human samples which saw little overall change in expression.
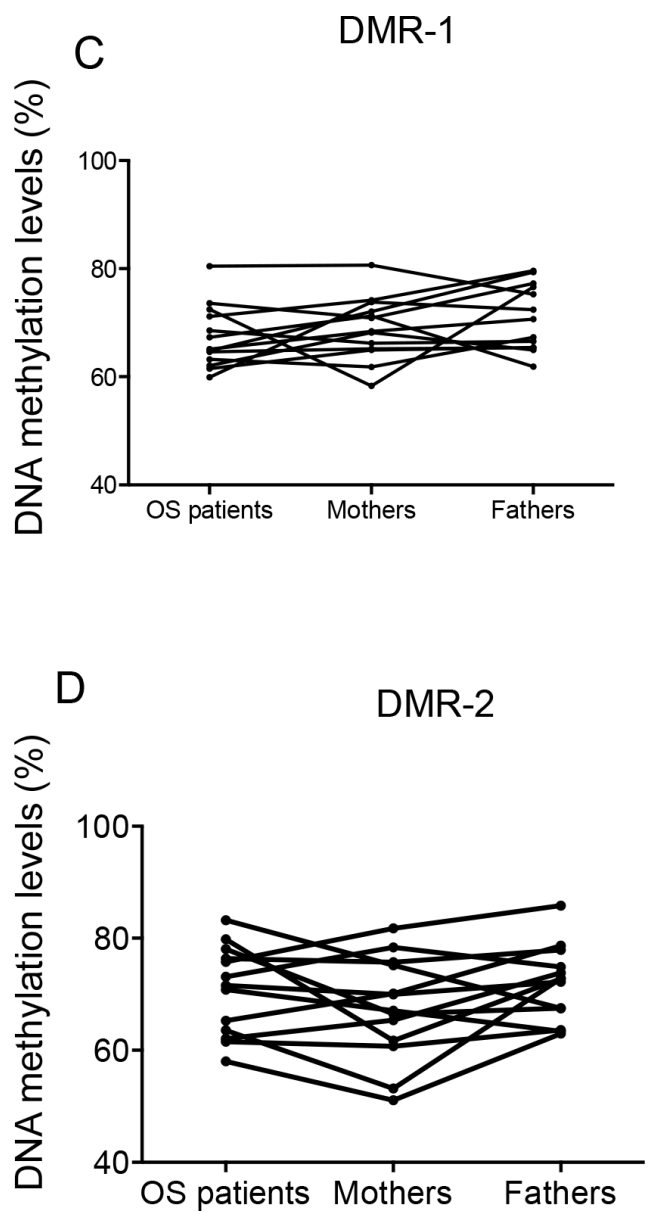

Figure 5: Imprinting defects at 14q32-locus in buccal tissue of osteosarcoma patients and their biological parents. (A) and (B) DNA methylation levels of DMR-1 and DMR-2 of buccal samples from normal subjects, osteosarcoma patients and their parents. One-way ANOVA was performed. ${ }^{*} P<0.05$. (C) and (D) The overlay graph of the DNA methylation levels of DMR-1 and DMR-2 of the OS family buccal samples. 


\section{4q-index is a prognostic indicator in osteosarcoma}

To determine whether the 14q-index can serve as a prognostic indicator in osteosarcoma, we tested an independent cohort of 15 human osteosarcoma biopsy samples obtained prior to chemotherapy/radiation with long-term clinical follow-up data. We again found significant imprinting defects at multiple loci, especially DMR-2 (Figure 7A), validating our previous results. Hypomethylation defects, especially at DMR-2, were present in the majority of samples and $86.7 \%$ (13 out of 15) samples showed an increase in the 14q-index. Combining these 15 new samples with the initial 21 osteosarcoma samples (onset at $<30$ years), we found a significant difference in the 14q-index in osteosarcoma patient samples with and without metastasis (Figure 7B). Additionally, osteosarcoma patients with imprinting defects and a high 14-q index had poorer survival outcomes (Figure 7C). With this limited sample size, a robust statistical analysis was not possible, however it was suggestive that patients with a normal 14q-index do have a survival advantage.

A
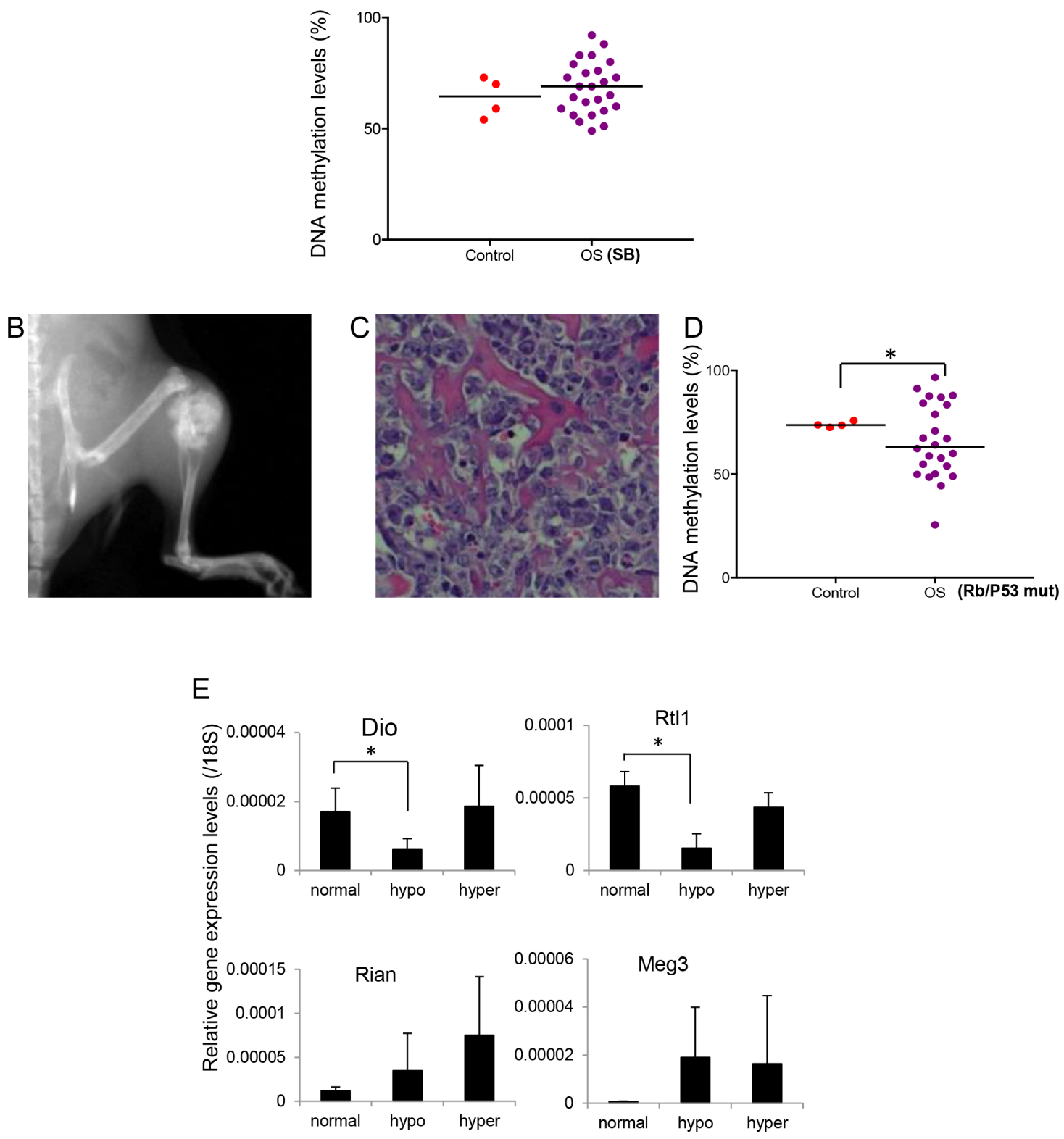

Figure 6: DNA methylation changes at 12qF DMR of spontaneous OS mouse models. (A) DNA methylation levels of $12 \mathrm{qF}$ DMR of Sleeping Beauty (T2/onc; p53R270H/+;OSx-Cre; ROSA26-LSL-SB11) induced OS samples. (B-C) Representative radiograph and histology section of osteosarcoma in mice homozygous for conditionally disrupted alleles of Trp53 and Rb1. (D) DNA methylation levels of 12qF DMR of p53/Rb1mut induced OS samples. $* P<0.05$. (E) Expression levels of imprinted genes in $12 \mathrm{qF}$ region in the p53/Rb1mut induced OS samples. $18 \mathrm{~s}$ rRNA was used as internal control. $* P<0.05$. 


\section{DISCUSSION}

The results of our study suggest that hypomethylation at $14 \mathrm{q} 32$ - imprinted IG-DMRs is predominantly associated with osteosarcoma (onset $<30$ years) and is a likely mechanism of downregulation of imprinted genes and miRNAs at this locus. Although hypomethylation typically leads to increased gene expression, it has been reported that hierarchical interaction of the methylation pattern in the three DMRs at the $14 \mathrm{q} 32$ locus does have a negative effect on gene expression [36, 37]. More importantly, the observed imprinting defects in 14q32 DMRs did not appear to be due to genome-wide methylation changes. DNA methylation patterns of $14 \mathrm{q} 32$ DMRs in osteosarcoma appear to be significantly different than those observed in other cancers and may provide additional insights into the pathobiology of osteosarcoma.
We developed the '14q-index' (14q-I) to quantitate the degree of imprinting defects in osteosarcoma and propose that $14 \mathrm{q}-\mathrm{I}(+)$ can be used as both a predictive marker of osteosarcoma and a prognostic indicator as patients with a normal index value tend to have improved survival outcomes.

We studied the effects of 14q32-locus imprinting defects on the expression of genes at this region. Notably, all the genes and miRNAs tested showed different degrees of downregulation [11]. Our data demonstrating that $14 \mathrm{q} 32$ locus genes (with the exception of MEG8) are significantly downregulated in osteosarcoma samples contradicts a previous report that loss-of-imprinting causes differential changes in paternal and maternal expressed genes and an inverse correlation at the IGF2-H19 locus [38]. This may be due to different regulatory mechanisms at the 14q32 and H19-IGF2 loci [39]. The imprinted genes

A

\begin{tabular}{|c|c|c|c|c|}
\hline ID & Age (years) & DMR-1 & DMR-2 & DMR-3 \\
\hline 1 & 16.7 & & & \\
\hline 2 & 17.1 & & & \\
\hline 3 & 25.3 & & & \\
\hline 4 & 16.7 & & & \\
\hline 5 & 16.5 & & & \\
\hline 6 & 20.3 & & & \\
\hline 7 & 18.6 & & & \\
\hline 8 & 11.4 & & & \\
\hline 9 & 15.1 & & & \\
\hline 10 & 15.1 & & & \\
\hline 11 & 8.0 & & & \\
\hline 12 & 8.6 & & & \\
\hline 13 & 13.7 & & & \\
\hline 14 & 13.8 & & & \\
\hline 15 & 9.5 & & & \\
\hline
\end{tabular}

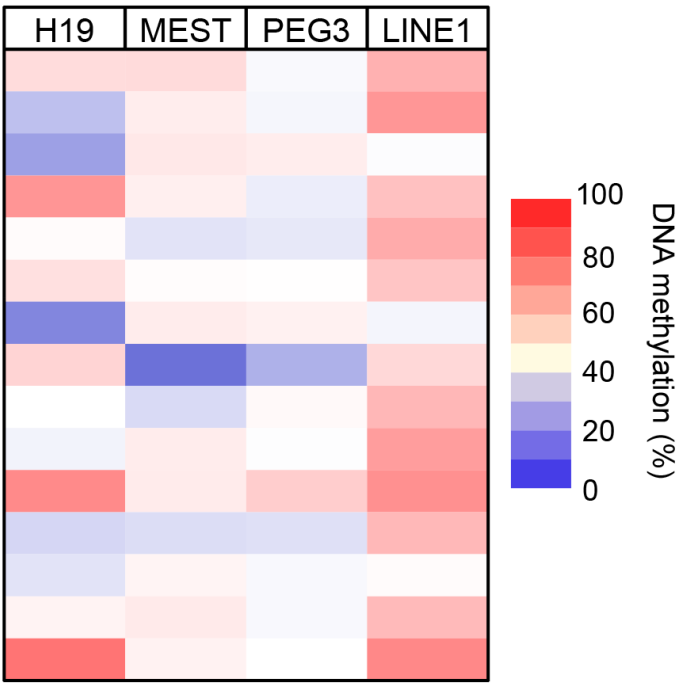

B

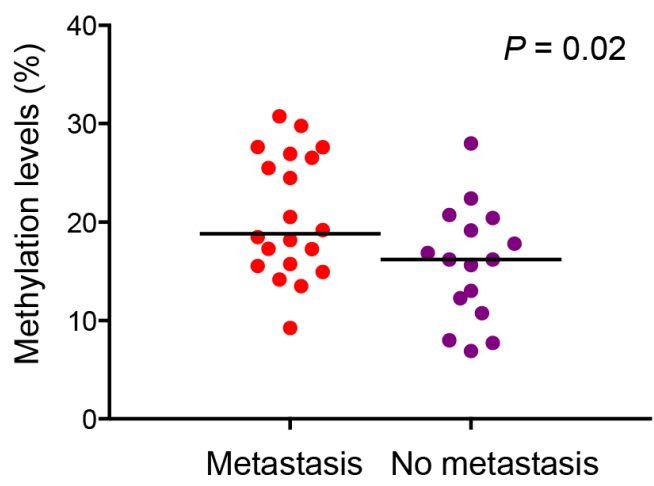

C

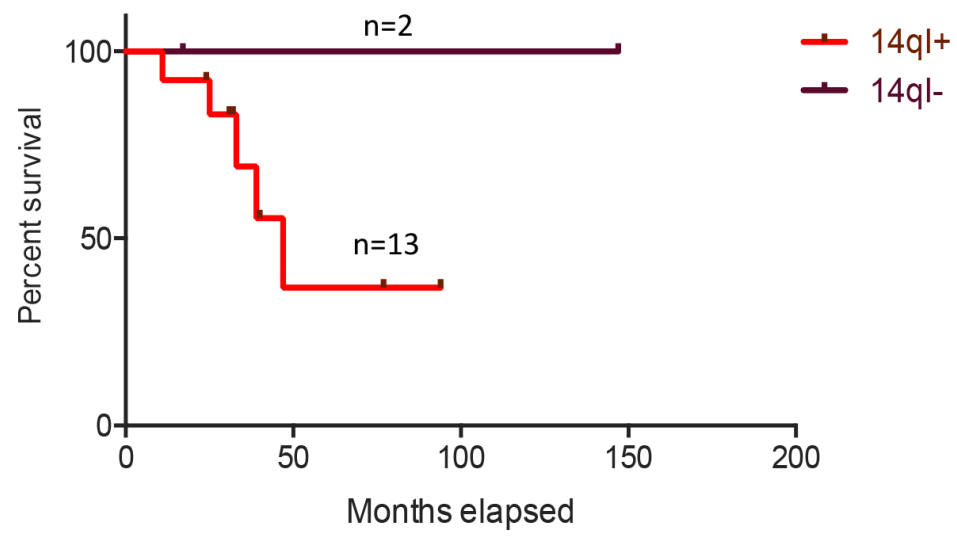

Figure 7: 14q-index as prognostic indicator in osteosarcoma. (A) DNA methylation levels of DMRs of 14q32-locus, three other imprinted loci, including H19, MEST and PEG3, and methylation levels of LINE1 in 15 biopsy samples analyzed by bisulfite pyrosequencing. (B) The difference of 14q-index between patients with and without metastasis in early-onset OS. (C) Survival analysis of OS patients with different 14q-index. 
at the 14q32-locus can be co-expressed in mesodermderived tissues and inversely expressed in lung, liver, and placenta [40]. It is likely that both the maternal and paternal imprinted genes are regulated as a single unit in bone tissue and imprinting defects can cause co-repression of both maternal and paternal expressed genes in osteosarcoma. It is interesting to note that imprinting defects have a differential impact on gene expression. In mice, the paternally and maternally expressed genes were inversely regulated with imprinting defects. However, in humans these genes were affected uniformly regardless of their parental origin, which may be due to the observed histone modifications.

There is a correlated pattern of $14 \mathrm{q} 32$ miRNA and DLK1-DIO3 gene cluster expression within individual patient samples. The genes at both ends of the cluster, $D L K 1$ and DIO3, showed more variability and this may implicate additional regulatory factors. Previously, we reported that significant downregulation of miRNAs from this locus was correlated with poor prognosis in human and canine osteosarcoma [41]. Consistent with these observations, our study also revealed that DLK1, RTL1, $D I O 3$, and miRNAs in this region are candidate proapoptotic genes [20]. MEG3 has been previously reported to function as a tumor suppressor that can regulate p53 expression [15]. Our results also suggested that imprinting defects at $M E G 3$-DMR (DMR-3) were not a significant contributor to cancer development but could potentially hasten the disease process. This finding was consistent with previous results suggesting that IG-DMRs are germline-derived primary DMRs, while MEG3-DMR is a post-fertilization-derived secondary DMR [42]. The IG-DMR acts hierarchically to regulate the methylation status of the somatic Glt2-DMR (homolog to human $M E G 3-\mathrm{DMR}$ ) in mice. Previously, we have reported that several 14q32 miRNAs function as tumor suppressors by targeting cMYC and that blocking these miRNAs using antimiRs in normal human osteoblasts was transformative [11]. Taken together, these data suggest that the $14 \mathrm{q} 32$ locus contains multiple tumor suppressors.

It has previously been suggested that the 14q32-imprinted locus may share similar regulatory mechanism(s) such as the IGF2-H19 imprinting cluster [43]. However, the patterns of co-expression or co-silencing are only found in the 14q32-locus, which implies different regulatory mechanisms between the two imprinted regions. We found that both the active marker H3K4-me3 and silenced marker H3K27-me3 were enriched in this 14q32-locus. We speculate that this locus is potentially controlled as a 'bivalent domain,' which is also associated with developmental and differentiation functions [44]. A bivalent domain is defined as the presence of both $\mathrm{H} 3 \mathrm{~K} 4-\mathrm{me} 3$ and H3K27-me3 at the same locus on the same allele simultaneously. We used the 14q32 IG-DMR region's DNA methylation status to define each allele's parental origin. The maternal allele is characteristically free from methylation while the paternal allele is densely methylated. Although Single Nucleotide Polymorphism (SNP) analysis would further confirm the presence of bivalent domain, we did not find suitable SNPs in this region for testing. These results suggested a possible mechanism for silencing of the entire 14q32imprinted genes and miRNAs in osteosarcoma samples, especially in $14 \mathrm{q}-\mathrm{I}(+)$ osteosarcoma cases. We also found that this entire imprinted region might be regulated as a single unit in bone tissues with the boundary marked between DLK1 and DIO3.

Imprinting defects at the 14q32-locus were found in $87 \%$ of osteosarcoma samples (onset $<30$ years). The specific loss of imprinting at the 14q32 and H19 loci in osteosarcoma samples suggested that these methylation changes were disease-specific and not the result of global methylation changes. Comparison of the DNA methylation patterns of 14q32 IG-DMRs in the buccal DNA samples of osteosarcoma patients, their biological parents, and unrelated normal subjects implied that imprinting instability exists in the affected child's parents but is absent in unrelated normal subjects. We speculate that inherited imprinting defects at the 14q32 locus may contribute to pediatric/young-adult development of osteosarcoma. Given the apparently 'normal' phenotype of the parents, imprinting instability itself is likely insufficient to cause cancer, but might predispose affected subjects to osteosarcoma.

It is of interest to note that osteosarcoma occurs predominantly during puberty, a period characterized by accelerated linear bone growth, and some imprinted genes in these regions have been implicated in bone differentiation. It is likely that under growth stimulation, patients with imprinting defects at $14 \mathrm{q} 32$ and associated silencing of multiple tumor suppressor genes are at greater risk of developing osteosarcoma. Similarly, lossof-imprinting at this locus is implicated in other cancers such as lymphoma, colon cancer, and neuroblastoma [45], which is also supported by our analysis of the imprinting status at 14q32-DMRs of 10 cancer cell lines representing six cancer types. In our study we clearly identified the differential methylation patterns in the normal ( $<30$ years) and late-onset osteosarcoma groups. It is possible that some of the pre-operative treatments that these patients received might also affect the epigenetic patterns although our sample collection criteria attempted to minimize this possibility. The timing of buccal sampling in patients with osteosarcoma may also have affected results, as some osteosarcoma drugs cause aggressive mouth sores [46].

Several mouse uni-parental disomy (UPD) models (pUPD12 and mUPD12) have been studied previously; these models are non-viable with skeletal and skeletal muscle defects. They suggested that imprinted genes on chromosome 12 are essential for the development of the mesodermal and neural crest-derived lineages that give rise to bone [47]. Skeletal abnormalities such 
as small hands, hyper-extensible joints and advanced bone age have been reported in human mUPD14 patients [48]. In osteosarcoma, imprinting defects at the 14q32-locus can cause significant downregulation of imprinted genes and miRNAs, which may further contribute to its pathobiology and disrupt normal skeletal development.

We generated mouse models of osteosarcoma by disrupting Trp53 in combination with either $S B$ transposon-mediated mutagenesis or concomitant loss of $R b 1$. We found that imprinting defects at $12 \mathrm{qF}$, the homolog to the human $14 \mathrm{q} 32$ locus, were quite uncommon in $S B$-induced osteosarcoma. In fact, their frequency was similar to that of human late-onset osteosarcoma, which is consistent with the hypothesis that mutations play a more causative role in the late-onset osteosarcoma development. In contrast, all Rb1/Trp53-mutant osteosarcoma mice had imprinting defects at $12 \mathrm{qF}$ DMRs, confirming that $12 \mathrm{qF}$-imprinting defects are an important mechanism for osteosarcoma development in this model.

Similar to our observations in normal/early (<30 years) and late-onset human osteosarcoma, there were distinctive $12 \mathrm{qF}$ locus methylation patterns between the two mouse models that may, in part, correspond to their genetic differences. The high frequency of imprinting defects in both the Rb1/Trp 53 model and in human osteosarcoma, suggested the presence of one or more conserved mechanisms in osteosarcoma development. $R b 1$ and/or Trp53 mutations along with imprinting defects may cooperatively function towards development and progression of osteosarcoma. The $S B$ mouse osteosarcomas have less genomic instability and chromothripsis, compared with Trp53 (no $S B$ ) or Rb1/Trp53 mouse osteosarcomas [49]. Further, only about $20 \%$ of $S B$ mice showed common insertion site mutagenesis in $R b 1$ [50]. $S B$-induced tumors may represent a model for the pathogenesis of late-onset osteosarcomas, which typically have had radiation exposure, prior alkylating chemotherapy, Paget's disease, or other mutationgenerating conditions or exposures. With rampant $S B$ mutations driving oncogenesis, epigenetic alterations may not be required to further drive the pathogenesis. Without a $S B$ mutagenesis program, it is possible that osteosarcoma development may require epigenetic modifications to induce cancer growth and maintenance. RB1 has epigenetic functions, which have not been well sorted out in osteosarcoma but previous publications have reported on the significant role of RB-loss in osteosarcoma [51, 52].

The overall change in 14q32 - DMR methylation status, quantitatively described as the $14 \mathrm{q}$-index, presents a promising indictor of diagnostic and prognostic significance that will need to be validated in a larger patient set. Using osteosarcoma patient samples and two mouse osteosarcoma models, our results indicate that normal/early-onset osteosarcoma (onset $<30$ years) is characterized by inherited imprinting defects that may contribute to osteosarcoma pathobiology, in contrast with late-onset osteosarcomas that appear to be driven more by different factors. These findings may provide new opportunities for improving the diagnosis and treatment options for osteosarcoma patients.

\section{MATERIALS AND METHODS}

\section{Cell lines, patients and normal tissue samples}

FUJI, SYO-1, HT-29, SW480, MPNST-14, MPNST-724, RD, RH30, MCF-7, SaOS2, U2OS, MG63, and HOS cell lines were used for methylation analyses, and cultured under established conditions [11,53]. Colon cancer cell lines HT-29 and SW480, synovial sarcoma cell lines SYO-1 and FUJ, rhabdomyosarcoma (RMS) cell lines Rh30 and RD, MPNST cell lines MPNST-14 and MPNST-724, breast cancer cell line MCF7, and osteosarcoma cell line SaOS2 were used in this study. Synovial sarcoma cell lines FUJI and SYO-1 were obtained from Dr. Torsten Nielsen (University of British Columbia), colon cancer cell lines HT-29, SW480, and MCF7 were kindly provided by Drs. Clifford Steer and Kathryn Schwertfeger (University of Minnesota), RMS cell line Rh30 was obtained from ATCC (CRL-2061), and RMS cell line RD was provided by Dr. Peter Houghton (St. Jude's Children's Research Hospital). MPNST cell lines were generously provided by Dr. Jonthan Fletcher, Harvard Medical School.

Osteosarcoma tissue samples were obtained from the tissue procurement facility at the University of Minnesota or from the Cooperative human tissue network. Dr. Logan Spector provided triad buccal DNA samples. All patient samples were obtained according to the University of Minnesota institutional review board (IRB) approved protocols. Osteosarcoma tissue samples with clinical follow-up were obtained from Leiden University Medical Center, The Netherlands. Available clinical and follow-up information for these samples are provided in Supplementary Table 1.

\section{DNA and RNA extraction and qRT-PCR}

DNA was extracted with a DNA Extraction kit from Qiagen, and RNA extraction was performed with a mirVana Total RNA Isolation kit (Life Technologies). Extractions were carried out according to the manufacturer's instructions. qRT-PCR was performed with $2 \mu \mathrm{g}$ DNase 1 treated total RNA using High Capacity RNAto-cDNA kit (Applied Biosystems); and PCR amplification was performed with SYBR Green I Master kit (Roche Applied Science) in a LightCycler 480. Primers were listed in Supplementary Table 2. GAPDH and $18 \mathrm{~s}$ rRNA were used as internal controls. 


\section{mRNA and miRNA RNA-Seq expression profiling}

To perform high-resolution quantification of mRNA and miRNA expression using RNA-Seq, we used at least $1 \mu \mathrm{g}$ of each pool of total RNA according to the mirVana Total RNA Isolation kit (Life Technologies). We sequenced mRNA libraries using $100 \mathrm{bp}$ paired-end runs on a HiSeq 2000 (Illumina) using v3 chemistry. miRNA libraries were sequenced using $50 \mathrm{bp}$ pairedend runs on a HiSeq 2500 (Illumina) using v4 chemistry. To quality-check raw-sequence FASTQ files, we used FastQC (http://www.bioinformatics.babraham.ac.uk/ projects/fastqc/). The TopHat2 algorithm was used to align the mRNA FASTQ files to the Human UCSC hg19 Assembly genome [54]. Next, to quantify the aligned reads against the reference human genome hg19 transcript annotations, we used Cufflinks and Cuffdiff, according to the standard Fragments Per Kilobase of transcript per Million mapped reads (FPKM) methods [55]. To quantitate miRNA expression levels, mature miRNA sequences were used to search miRNA FASTQ files and normalized to Counts per Million total reads for each sample. For statistical analysis and clustering, we used the Partek Genomics Suite software package (Partek Inc). FPKM (mRNA) or Counts per Million total reads (miRNA) values were log base 2 transformed and mean centered before clustering.

\section{DNA bisulfite pyrosequencing and TA cloning and sequencing}

Bisulfate DNA treatment, pyrosequencing and TA cloning and sequencing were performed as previously described [56]. Normal buccal samples were used as control for bisulfite treatment. Two rounds of PCR were carried out to synthesize biotin-labeled specified PCR products with the primers listed in Supplementary Table 2. TA cloning and sequencing were also used in selected samples. Bisulfite-PCR products were cloned into a pCR4.0-TOPO vector and 6 10 clones were selected and sequenced. Methylation levels were calculated as the average value of the selected clones [57].

\section{Chromatin immunoprecipitation (ChIP) assays}

The ChIP assay was performed as previously described [58]. Three $\sim 50 \mathrm{mg}$ tissue samples of different groups (normal bone tissue, 14q index (-), and 14q index $(+))$ were treated with formaldehyde to cross-link histone to DNA. After sonication and pre-cleaning, the samples were incubated with 3 5 $\mu 1$ anti-H3K4me3, H3K27-me3, and $\mathrm{IgG}$ (Millipore) at $4{ }^{\circ} \mathrm{C}$ overnight, respectively, and then with Dynal Magnetic beads from Invitrogen for 1 hour at $4^{\circ} \mathrm{C}$. After washing, immunoprecipitated complexes were eluted and histone-DNA crosslinks were reversed. DNA was extracted, and real-time PCR was used to quantify the immunoprecipitated DNA.

\section{Plasmid construction, cell proliferation and apoptosis analyses}

Human DIO3 and RTL1 coding sequences were amplified and cloned into pcDNA3.1 (Invitrogen) by $X b a \mathrm{I}$ and XhoI. Human DLKl overexpression plasmid was obtained from Origene. SaOS2 cells were planted in 48 well plates 24 hours before transfection. A total of $0.4 \mu \mathrm{g}$ overexpression constructs were transfected into $\mathrm{SaOS} 2$ cells with lipofectamine. The same amount of pcDNA3.1 empty vector was used as control. Cell proliferation was determined after transfection for $72 \mathrm{hrs}$ using Cell Titer 96 Aqueous One Solution Cell Proliferation Assay (Promega) in a Synergy 2 microplate reader. Apoptosis assays were conducted with the Vybrant apoptosis assay kit \#8 (Molecular Probes, Invitrogen) on a BD FACS Canto II according to the manufacturer's instruction.

\section{Spontaneous osteosarcoma mice models}

Tumor and matched normal bone tissue samples obtained from Sleeping Beauty [50] (T2/onc; p53 $3^{\text {R270 }}$ ${ }^{\mathrm{H} /+}$;OSX-Cre; ROSA26-LSL-SB11) induced osteosarcoma mouse models were used to determine the methylation levels of $12 \mathrm{qF}$ DMR regions. Tumor and matched normal bone tissue samples were obtained from mice homozygous for conditionally disrupted alleles of $\operatorname{Trp} 53$ and $R b 1$, induced by PrxlCre as described previously [59]. Schematic representation for generation of (Prx1Cre;Rb1$\mathrm{fl} / \mathrm{fl}$; $\operatorname{Trp} 53-\mathrm{fl} / \mathrm{fl}$ ) osteosarcoma in mice homozygous for conditionally disrupted alleles of $\operatorname{Trp} 53$ and $R b 1$ is given is Supplementary Figure 3. All animal studies were IACUC approved; and details used in the study are provided in Supplementary Tables 4 and 5.

\section{Statistics}

Statistical analysis such as mean, standard deviation, were calculated for each group analyses and the standard error was used as an index for variability. Student twotailed $t$-test was performed for statistical analysis. The unpaired $t$-test was used to compare patient samples; and the paired $t$-test for apoptosis, cell proliferation assays and buccal tissue of osteosarcoma family member studies. One-way ANOVA was used in the family sample studies. Kaplan-Meier curve was used in the patient survival outcome studies.

\section{ACKNOWLEDGMENTS}

We thank Drs. Kevin B. Jones and Branden Moriarity for generating and providing mouse osteosarcoma samples and Drs. Jaime Modiano, Aaron Sarver and Reena Kartha for their helpful comments. We thank Drs. Anne-Marie Cleaton and Pancras Hogendoorn, Leiden University Medical Center for providing osteosarcoma samples with 
clinical follow-up information. We thank Dr. Xiaopin Cai for technical support.

\section{GRANT SUPPORT}

Grant funding from the American Cancer Society (RSG-13-381-01), Wyckoff Sarcoma Foundation, the Children's Cancer Research Fund and Sobiech osteosarcoma fund to SS are duly acknowledged.

\section{CONFLICTS OF INTEREST}

The authors have declared no conflicts of interests.

\section{REFERENCES}

1. Foster L, Dall GF, Reid R, Wallace WH, Porter DE. Twentieth-century survival from osteosarcoma in childhood. Trends from 1933 to 2004. J Bone Joint Surg Br. 2007; 89:1234-1238.

2. Chandar N, Billig B, McMaster J, Novak J. Inactivation of p53 gene in human and murine osteosarcoma cells. Br J Cancer. 1992; 65:208-214.

3. McIntyre JF, Smith-Sorensen B, Friend SH, Kassell J, Borresen AL, Yan YX, Russo C, Sato J, Barbier N, Miser J, et al. Germline mutations of the p53 tumor suppressor gene in children with osteosarcoma. J Clin Oncol. 1994; 12:925-930.

4. Heinsohn S, Evermann U, Zur Stadt U, Bielack S, Kabisch H. Determination of the prognostic value of loss of heterozygosity at the retinoblastoma gene in osteosarcoma. Int J Oncol. 2007; 30:1205-1214.

5. Benassi MS, Molendini L, Gamberi G, Ragazzini P, Sollazzo MR, Merli M, Asp J, Magagnoli G, Balladelli A, Bertoni F, Picci P. Alteration of pRb/p16/cdk4 regulation in human osteosarcoma. Int J Cancer. 1999; 84:489-493.

6. Kansara M, Tsang M, Kodjabachian L, Sims NA, Trivett MK, Ehrich M, Dobrovic A, Slavin J, Choong PF, Simmons PJ, Dawid IB, Thomas DM. Wnt inhibitory factor 1 is epigenetically silenced in human osteosarcoma, and targeted disruption accelerates osteosarcomagenesis in mice. J Clin Invest. 2009; 119:837-851.

7. Oh JH, Kim HS, Kim HH, Kim WH, Lee SH. Aberrant methylation of p14ARF gene correlates with poor survival in osteosarcoma. Clin Orthop Relat Res. 2006; 442:216-222.

8. Harada K, Toyooka S, Maitra A, Maruyama R, Toyooka KO, Timmons CF, Tomlinson GE, Mastrangelo D, Hay RJ, Minna JD, Gazdar AF. Aberrant promoter methylation and silencing of the RASSF1A gene in pediatric tumors and cell lines. Oncogene. 2002; 21:4345-4349.

9. Ulaner GA, Vu TH, Li T, Hu JF, Yao XM, Yang Y, Gorlick R, Meyers P, Healey J, Ladanyi M, Hoffman AR. Loss of imprinting of IGF2 and H19 in osteosarcoma is accompanied by reciprocal methylation changes of a CTCFbinding site. Hum Mol Genet. 2003; 12:535-549.
10. Lee DF, Su J, Kim HS, Chang B, Papatsenko D, Zhao R, Yuan Y, Gingold J, Xia W, Darr H, Mirzayans R, Hung MC, Schaniel C, et al. Modeling familial cancer with induced pluripotent stem cells. Cell. 2015; 161:240-254.

11. Thayanithy V, Sarver AL, Kartha RV, Li L, Angstadt AY, Breen M, Steer CJ, Modiano JF, Subramanian S. Perturbation of 14q32 miRNAs-cMYC gene network in osteosarcoma. Bone. 50:171-181.

12. Cavaille J, Seitz H, Paulsen M, Ferguson-Smith AC, Bachellerie JP. Identification of tandemly-repeated C/D snoRNA genes at the imprinted human $14 \mathrm{q} 32$ domain reminiscent of those at the Prader-Willi/Angelman syndrome region. Hum Mol Genet. 2002; 11:1527-1538.

13. Charlier C, Segers K, Wagenaar D, Karim L, Berghmans S, Jaillon O, Shay T, Weissenbach J, Cockett N, Gyapay G, Georges M. Human-ovine comparative sequencing of a 250-kb imprinted domain encompassing the callipyge (clpg) locus and identification of six imprinted transcripts: DLK1, DAT, GTL2, PEG11, antiPEG11, and MEG8. Genome Res. 2001; 11:850-862.

14. Wang Y, Sul HS. Pref-1 regulates mesenchymal cell commitment and differentiation through Sox9. Cell Metab. 2009; 9:287-302.

15. Benetatos L, Vartholomatos G, Hatzimichael E. MEG3 imprinted gene contribution in tumorigenesis. Int J Cancer. 129:773-779.

16. Sekita Y, Wagatsuma H, Nakamura K, Ono R, Kagami M, Wakisaka N, Hino T, Suzuki-Migishima R, Kohda T, Ogura A, Ogata T, Yokoyama M, Kaneko-Ishino T, et al. Role of retrotransposon-derived imprinted gene, Rtl1, in the feto-maternal interface of mouse placenta. Nat Genet. 2008; 40:243-248.

17. Abdallah BM, Jensen $\mathrm{CH}$, Gutierrez $\mathrm{G}$, Leslie $\mathrm{RG}$, Jensen TG, Kassem M. Regulation of human skeletal stem cells differentiation by Dlk1/Pref-1. J Bone Miner Res. 2004; 19:841-852.

18. Abdallah BM, Ding M, Jensen CH, Ditzel N, Flyvbjerg A, Jensen TG, Dagnaes-Hansen F, Gasser JA, Kassem M. Dlk1/FA1 is a novel endocrine regulator of bone and fat mass and its serum level is modulated by growth hormone. Endocrinology. 2007; 148:3111-3121.

19. Liu L, Luo GZ, Yang W, Zhao X, Zheng Q, Lv Z, Li W, Wu HJ, Wang L, Wang XJ, Zhou Q. Activation of the imprinted Dlk1-Dio3 region correlates with pluripotency levels of mouse stem cells. J Biol Chem. 2010; 285: 19483-19490.

20. Benetatos L, Hatzimichael E, Londin E, Vartholomatos G, Loher P, Rigoutsos I, Briasoulis E. The microRNAs within the DLK1-DIO3 genomic region: involvement in disease pathogenesis. Cell Mol Life Sci. 2013; 70:795-814.

21. Benetatos L, Voulgaris E, Vartholomatos G. DLK1-MEG3 imprinted domain microRNAs in cancer biology. Crit Rev Euk Gene Exp. 2012; 22:1-15.

22. Reik W, Walter J. Genomic imprinting: parental influence on the genome. Nat Rev Genet. 2001; 2:21-32. 
23. Ferguson-Smith AC, Surani MA. Imprinting and the epigenetic asymmetry between parental genomes. Science. 2001; 293:1086-1089.

24. Feil R, Khosla S. Genomic imprinting in mammals: an interplay between chromatin and DNA methylation? Trends Genet. 1999; 15:431-435.

25. Ogawa O, Becroft DM, Morison IM, Eccles MR, Skeen JE, Mauger DC, Reeve AE. Constitutional relaxation of insulinlike growth factor II gene imprinting associated with Wilms' tumour and gigantism. Nat Genet. 1993; 5:408-412.

26. Ogawa O, Eccles MR, Szeto J, McNoe LA, Yun K, Maw MA, Smith PJ, Reeve AE. Relaxation of insulinlike growth factor II gene imprinting implicated in Wilms' tumour. Nature. 1993; 362:749-751.

27. Nakagawa $H$, Chadwick RB, Peltomaki P, Plass C, Nakamura Y, de La Chapelle A. Loss of imprinting of the insulin-like growth factor II gene occurs by biallelic methylation in a core region of H19-associated CTCFbinding sites in colorectal cancer. Proc Natl Acad Sci U S A. 2001; 98:591-596.

28. Kaneda A, Feinberg AP. Loss of imprinting of IGF2: a common epigenetic modifier of intestinal tumor risk. Cancer Res. 2005; 65:11236-11240.

29. Kagami M, Sekita Y, Nishimura G, Irie M, Kato F, Okada M, Yamamori S, Kishimoto H, Nakayama M, Tanaka Y, Matsuoka K, Takahashi T, Noguchi M, et al. Deletions and epimutations affecting the human $14 \mathrm{q} 32.2$ imprinted region in individuals with paternal and maternal upd(14)-like phenotypes. Nat Genet. 2008; 40:237-242.

30. Zhao J, Ohsumi TK, Kung JT, Ogawa Y, Grau DJ, Sarma K, Song JJ, Kingston RE, Borowsky M, Lee JT. Genome-wide identification of polycomb-associated RNAs by RIP-seq. Mol Cell. 2010; 40:939-953.

31. Mirabello L, Troisi RJ, Savage SA. Osteosarcoma incidence and survival rates from 1973 to 2004: data from the Surveillance, Epidemiology, and End Results Program. Cancer. 2009; 115:1531-1543.

32. Yang AS, Estecio MR, Doshi K, Kondo Y, Tajara EH, Issa JP. A simple method for estimating global DNA methylation using bisulfite PCR of repetitive DNA elements. Nucl Acid Res. 2004; 32:e38.

33. Zhang Y, Shu J, Si J, Shen L, Estecio MR, Issa JP. Repetitive elements and enforced transcriptional repression co-operate to enhance DNA methylation spreading into a promoter CpG-island. Nucl Acids Res. 2012; 40:7257-7268.

34. Toyota M, Issa JP. CpG island methylator phenotypes in aging and cancer. Semin Cancer Biol. 1999; 9:349-357.

35. Olive KP, Tuveson DA, Ruhe ZC, Yin B, Willis NA, Bronson RT, Crowley D, Jacks T. Mutant p53 gain of function in two mouse models of Li-Fraumeni syndrome. Cell. 2004; 119:847-860.

36. Kagami M, O’Sullivan MJ, Green AJ, Watabe Y, Arisaka O, Masawa N, Matsuoka K, Fukami M, Matsubara K, Kato F,
Ferguson-Smith AC, Ogata T. The IG-DMR and the MEG3-DMR at human chromosome 14q32.2: hierarchical interaction and distinct functional properties as imprinting control centers. PLoS Genet. 2010; 6:e1000992.

37. Kagami M, Mizuno S, Matsubara K, Nakabayashi K, Sano S, Fuke T, Fukami M, Ogata T. Epimutations of the IGDMR and the MEG3-DMR at the 14q32.2 imprinted region in two patients with Silver-Russell syndrome-compatible phenotype. Euro J Hum Genet. 2015; 23:1062-1067

38. Steenman MJ, Rainier S, Dobry CJ, Grundy P, Horon IL, Feinberg AP. Loss of imprinting of IGF2 is linked to reduced expression and abnormal methylation of H19 in Wilms' tumour. Nat Genet. 1994; 7:433-439.

39. Wylie AA, Murphy SK, Orton TC, Jirtle RL. Novel imprinted DLK1/GTL2 domain on human chromosome 14 contains motifs that mimic those implicated in IGF2/H19 regulation. Genome Res. 2000; 10:1711-1718.

40. da Rocha ST, Tevendale M, Knowles E, Takada S, Watkins M, Ferguson-Smith AC. Restricted co-expression of Dlk1 and the reciprocally imprinted non-coding RNA, Gt12: implications for cis-acting control. Dev Biol. 2007; 306:810-823.

41. Sarver AL, Thayanithy V, Scott MC, Cleton-Jansen AM, Hogendoorn PC, Modiano JF, Subramanian S. MicroRNAs at the human 14q32 locus have prognostic significance in osteosarcoma. Orph J Rare Dis. 2013; 8:7.

42. Lin SP, Youngson N, Takada S, Seitz H, Reik W, Paulsen M, Cavaille J, Ferguson-Smith AC. Asymmetric regulation of imprinting on the maternal and paternal chromosomes at the Dlk1-Gt12 imprinted cluster on mouse chromosome 12. Nat Genet. 2003; 35:97-102.

43. Kawakami T, Chano T, Minami K, Okabe H, Okada Y, Okamoto K. Imprinted DLK1 is a putative tumor suppressor gene and inactivated by epimutation at the region upstream of GTL2 in human renal cell carcinoma. Hum Mol Genet. 2006; 15:821-830.

44. Moon YS, Smas CM, Lee K, Villena JA, Kim KH, Yun EJ, Sul HS. Mice lacking paternally expressed Pref-1/Dlk1 display growth retardation and accelerated adiposity. Mol Cell Biol. 2002; 22:5585-5592.

45. Astuti D, Latif F, Wagner K, Gentle D, Cooper WN, Catchpoole D, Grundy R, Ferguson-Smith AC, Maher ER. Epigenetic alteration at the DLK1-GTL2 imprinted domain in human neoplasia: analysis of neuroblastoma, phaeochromocytoma and Wilms' tumour. B J Cancer. 2005; 92:1574-1580.

46. Janeway KA, Grier HE. Sequelae of osteosarcoma medical therapy: a review of rare acute toxicities and late effects. Lancet Oncol. 2010; 11:670-678.

47. Georgiades P, Watkins M, Surani MA, Ferguson-Smith AC. Parental origin-specific developmental defects in mice with uniparental disomy for chromosome 12. Development. 2000; 127:4719-4728. 
48. Kotzot D. Maternal uniparental disomy 14 dissection of the phenotype with respect to rare autosomal recessively inherited traits, trisomy mosaicism, and genomic imprinting. Annal Genet. 2004; 47:251-260.

49. Jones KB. Transposon mutagenesis disentangles osteosarcoma genetic drivers. Nat Genet. 2015; 47:564-565.

50. Moriarity BS, Otto GM, Rahrmann EP, Rathe SK, Wolf NK, Weg MT, Manlove LA, LaRue RS, Temiz NA, Molyneux SD, Choi K, Holly KJ, Sarver AL, et al. A Sleeping Beauty forward genetic screen identifies new genes and pathways driving osteosarcoma development and metastasis. Nat Genet. 2015; 47:615-624.

51. Sosa-Garcia B, Gunduz V, Vazquez-Rivera V, Cress WD, Wright G, Bian H, Hinds PW, Santiago-Cardona PG. A role for the retinoblastoma protein as a regulator of mouse osteoblast cell adhesion: implications for osteogenesis and osteosarcoma formation. PLoS One. 2010; 5:e13954.

52. Berman SD, Calo E, Landman AS, Danielian PS, Miller ES, West JC, Fonhoue BD, Caron A, Bronson R, Bouxsein ML, Mukherjee S, Lees JA. Metastatic osteosarcoma induced by inactivation of $\mathrm{Rb}$ and $\mathrm{p} 53$ in the osteoblast lineage. Proc Natl Acad Sci. 2008; 105:11851-11856.

53. Li L, Sarver AL, Alamgir S, Subramanian S. Downregulation of microRNAs miR-1, -206 and -29 stabilizes PAX3 and CCND2 expression in rhabdomyosarcoma. Lab Invest. 92:571-583.
54. Kim D, Pertea G, Trapnell C, Pimentel H, Kelley R, Salzberg SL. TopHat2: accurate alignment of transcriptomes in the presence of insertions, deletions and gene fusions. Genome Biol. 2013; 14:R36.

55. Trapnell C, Williams BA, Pertea G, Mortazavi A, Kwan G, van Baren MJ, Salzberg SL, Wold BJ, Pachter L. Transcript assembly and quantification by RNA-Seq reveals unannotated transcripts and isoform switching during cell differentiation. Nat Biotech. 2010; 28:511-515.

56. Shu J, Jelinek J, Chang H, Shen L, Qin T, Chung W, Oki Y, Issa JP. Silencing of bidirectional promoters by DNA methylation in tumorigenesis. Cancer Res. 2006; 66:5077-5084.

57. Toyota M, Ho C, Ohe-Toyota M, Baylin SB, Issa JP. Inactivation of CACNA1G, a T-type calcium channel gene, by aberrant methylation of its $5^{\prime} \mathrm{CpG}$ island in human tumors. Cancer Res. 1999; 59:4535-4541.

58. Bonte E, Becker PB. Preparation of chromatin assembly extracts from preblastoderm Drosophila embryos. Methods Mol Biol. 1999; 119:187-194.

59. Quist T, Jin H, Zhu JF, Smith-Fry K, Capecchi MR, Jones KB. The impact of osteoblastic differentiation on osteosarcomagenesis in the mouse. Oncogene. 2015; $34: 4278-4284$. 